\title{
LES MÉTHODES DE DOSAGE DES PRINCIPALES VITAMINES HYDROSOLUBLES (1)
}

\author{
PAR \\ Jean ADRLAN \\ Attaché de Recherches au C. N. R. S. \\ Laboratoire de Biochimie de la Nutrition (Bellevue).
}

\section{A. - INTRODUCTION}

Bien que de découverte souvent très récente, les vitamines hydrosolubles ont suscité un grand nombre de méthodes de dosages, basées sur des principes variés.

A cette abondance et à cette diversité on peut voir plusieurs raisons :

- la recherche des résultats spécifiques a multiplié les méthodes et les modalités opératoires ;

- on ne cherche pas toujours le même résultat : tantôt on désire doser une molécule chimique définie (industrie pharmaceutique), tantôt on s'intéressera à l'efficacité vitaminique (dans le cas d'un aliment par exemple) ;

- enfin, la multiplicité des méthodes est avant tout redevable des progrès que l'on a fait dans la connaissance biochimique des vitamines.

Cette connaissance s'est faite en 3 étapes principales, et à chacune d'elles correspond un type de méthode de dosages :

a) la première étape a été marquée par la découverte des symptômes cliniques d'avitaminoses et l'attribution de ces " maladies " à des carences alimentaires.

A cette époque, on mesurait la valeur vitaminique des aliments en recherchant leur efficacité à protéger les animaux (cobaye, souris, rat) de l'avitaminose, ou, au contraire, à restaurer ces animaux après les avoir carencés.

Les résultats de ces méthodes biologiques sont exprimés en unités mal définies, et surtout chaque laboratoire possède ses Unités propres.

b) Ensuite les biochimistes ont découvert les molécules chimiques des diverses vitamines, acide ascorbique, thiamine, riboflavine, etc.

On a pu alors doser ces molécules dans les aliments et les divers

(') Cours-conférence donné le I4 mai $195^{6}$ à la Maison de la Chimie, sous les auspices du Centre de perfectionnement technique. 
matériaux, et les résultats de ces méthodes chimiques sont exprimés en milligrammes de thiamine, ou riboflavine, etc.

Les résultats sont donc comparables d'un laboratoire à 1'autre, et les méthodes sont plus spécifiques.

c) Enfin, récemment, il a été mis en évidence que l'efficacité vitaminique d'un aliment était la résultante de l'activité d'un ou plusieurs corps chimiques, les uns possédant une activité vitaminique plus ou moins grande par rapport à la vitamine elle-même (famille B6 et acide folique), les autres possédant des propriétés anti-vitaminiques (thiaminase).

Parallèlement, se sont développées des méthodes microbiologiques de dosages vitaminiques, qui permettent de mesurer une efficacité biologique à l'aide de souches bactériennes diverses.

Il existe ainsi actuellement 3 grands types de dosages vitaminiques : biologique, chimique et microbiologique. Nous allons les passer successivement en revue, mais auparavant nous rappelons les principales caractéristiques physiques des vitamines hydrosolubles. Quelle que soit la méthode adoptée, il faudra en effet se placer dans des conditions qui respectent l'intégralité de la vitamine.

\section{Conditions de conservation et de destruction des vitamines.}

Vitamine

Acide ascorbique.

Thiamine

Riboflavine

Niacine

Acide pantothénique

Biotine

Vitamine B 6

Acide folique

Vitamine B I 2
Conditions de stabilité

A l'obscurité.

Sans oxygène en milieu acide ou neutre, même à chaud.

En milieu acide $(\mathrm{pH} 6,5)$.

Stable en milieu acide. Assez résistante à la chaleur.

Thermostable. Résiste à l'oxydation. Stable en milieu acide et alcalin.

Stable à la chaleur entre $\mathrm{pH} 5,0$ et 7,0 . Stable à l'oxygène et aux oxydants.

Thermostable. Stable en milieu acide.

Stable aux acides et aux bases. Thermostable.

Stable en milieu neutre ou alcalin, à chaud.

Stable à chaud en présence de $\mathrm{CN} \mathrm{K}$. Stable en sérum physiologique.
CONDITIONS DE DESTRUCTION

L'oxygène le décompose particulièrement en milieu alcalin, les oxydants le détruisent extrêmement facilement, les catalyseurs d'oxydation le détruisent (cuivre, fer).

Relativement thermolabile. Détruite en milieu neutre ou alcalin. Sensible à l'oxydation et au cuivre.

Très photosensible. Détruite dès que le milieu atteint ou dépasse la neutralité (verre alcain). Sensible aux réducteurs.

Sensible aux acides et aux bases.

Oxydable.

Photosensible en milieu neutre ou alcalin. Sensible aux oxydants.

Photosensible. Détruit par les acides. Oxydable.

Photosensible. Sensible aux acides et aux bases. 


\section{B. - LES MÉTHOdes BIOLOGIQUES}

Ce sont les méthodes les plus anciennes et en même temps celles qui reflètent le mieux "l'efficacité vitaminique " d'un échantillon. Ellles sont basées sur la prévention ou la guérison d'un animal soumis à un régime carencé.

\section{Généralités}

On utilise dans cette technique le Rat pris au sevrage ou le Poussin d'un jour, c'est-à-dire des animaux n'ayant pas encore accumulé de réserves vitaminiques propres. Le dosage de l'acide ascorbique faisant exception car il emploie des cobayes adultes. C'est la seule vitamine dont on puisse réaliser des carences sur animaux adultes.

La méthode préventive ou " test de croissance " de l'animal demande tout d'abord une courte prépériode pour enlever à l'animal ses surplus vitaminiques. On obtient ce résultat en soumettant les Rats au régime de carence pendant quelques jours, ou les Poussins pendant une durée plus courte.

A ce moment-là on constitue les lots expérimentaux avec le plus grand soin possible en répartissant dans chaque lot un nombre égal d'animaux du même sexe (mâle), provenant des mêmes mères, et de poids égal avant et après la prépériode. Cette opération est très importante et conditionne l'exactitude du dosage.

Chaque lot doit contenir le même nombre d'animaux (de 8 à I2). Une fois les lots ainsi établis, on fournit à certains lots des quantités croissantes de vitamine pure qui permettent d'établir une courbe-étalon, tandis que d'autres lots reçoivent des quantités connues de l'échantillon à doser, et ceci à 2 ou 3 niveaux différents. Il convient que la substance soit suffisamment riche en vitamine pour que les quantités à foumir aux animaux ne représentent qu'un faible pourcentage de la ration. De plus, on doit corriger la composition du régime de base en fonction de la nature de l'échantillon : par exemple, si on désire connaître la valeur vitaminique d'une poudre de viande on retranchera du régime de base une quantité de caséine égale à la quantité de l'échantillon introduite dans les lots expérimentaux : ainsi tous les lots seront au même niveau azoté. Si on analyse des échantillons de céréales, on retranchera du régime de base une partie du sucre, etc.

A titre d'exemple, on peut constituer les lots suivants pour le dosage biologique d'une des vitamines $B$ : 


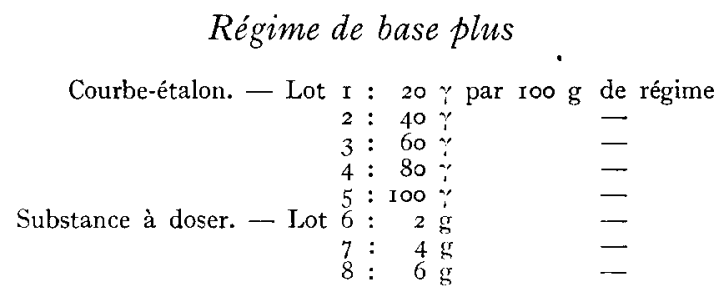

Originellement la période expérimentale s'étendait sur 4 semaines environ, puis on l'a ramenée à I5 ou même ro jours. Quoiqu'il en soit, à la fin de l'essai, on mesure les gains de poids des différents lots et en intrapolant les augmentations pondérales des lots expérimentaux par rapport à celles des lots constituant la courbe-étalon, on en déduit la teneur vitaminique du produit analysé.

Ia méthode curative ou " test de restauration " des animaux ne commence que lorsque les animaux sont en état de carence vitaminique aiguë, c'est-à-dire quand les symptômes cliniques sont nettement apparents. Dans ce cas, la prépériode est évidemment plus longue, surtout pour le Rat (6 à 9 semaines). Les animaux sont répartis en lots comme précédemment, avec la même attention ; il faut ici que tous les lots présentent le même tableau clinique.

Chaque lot reçoit un supplément vitaminique soit sous forme de vitamine pure, soit sous forme de substance à analyser. Au bout de quelques semaines on note le pourcentage d'animaux guéris dans les différents lots. De là on bâtit une courbe-étalon et on calcule la teneur vitaminique de 1'échantillon.

Dans d'autres cas, on mesure le gain de poids des animaux pendant la période de la restauration. Mais, en aucun cas, on ne peut se baser sur la vitesse de restauration des animaux, qui, elle, n'est pas uniquement fonction de la teneur de la ration en vitamine.

Du reste, la spécificité reste la difficulté majeure de ce type de dosage. En effet, d'une part la ration de base doit être complète et équilibrée, et d'autre part la composition de la ration (glucides, lipides) ou la nature de l'échantillon ne doit pas influencer la réponse de l'animal. C'est ainsi que la découverte des derniers membres du complexe $B$ a pu jeter une suspicion sur les résultats antérieurs des méthodes biologiques, car les rations de base risquaient d'être partiellement déficientes en facteurs alors inconnus (la remarque est encore valable de nos jours) ; par ailleurs, dans le cas d'un dosage de niacine, par exemple, ni la ration, ni surtout l'échantillon ne doivent renfermer de tryptophane, l'interrelation existant entre ces 2 métabolites faussant la réponse de 1'animal.

On peut faire à ces méthodes un reproche d'ordre matériel, c'est l'effort, le temps et les frais qu'elles nécessitent. Il est bien difficile de les utiliser dans le travail courant. 
Ces méthodes biologiques n'en présentent pas moins des avantages certains. Ce sont elles qui ont le plus de chances de fournir des résultats valables pour l'Homme. De plus, elles mesurent l'efficacité vitaminique " réelle ", et permettent de découvrir les facteurs d'épargne et les "indisponibilités " éventuelles existant dans certains aliments : en fait, elles dosent la vitamine utilisable et non la vitamine totale.

Un autre avantage des techniques biologiques sur les méthodes chimiques et microbiologiques est de pouvoir donner l'échantillon sous sa forme naturelle, sans avoir besoin de libérer la vitamine par une hydrolyse chimique ou enzymatique. Cette hydrolyse est très souvent cause de résultats erronés.

La composition de la ration est évidemment d'une importance capitale. Pour la plupart des facteurs, on peut partir de cette ration ci dessous complète et équilibrée en supprimant la vitamine à doser. Voici, à titre indicatif, une ration de croissance pour le Rat, qui permet un gain de poids journalier de $4 \mathrm{~g}$.

\section{Pour I $k g$ de ration:}
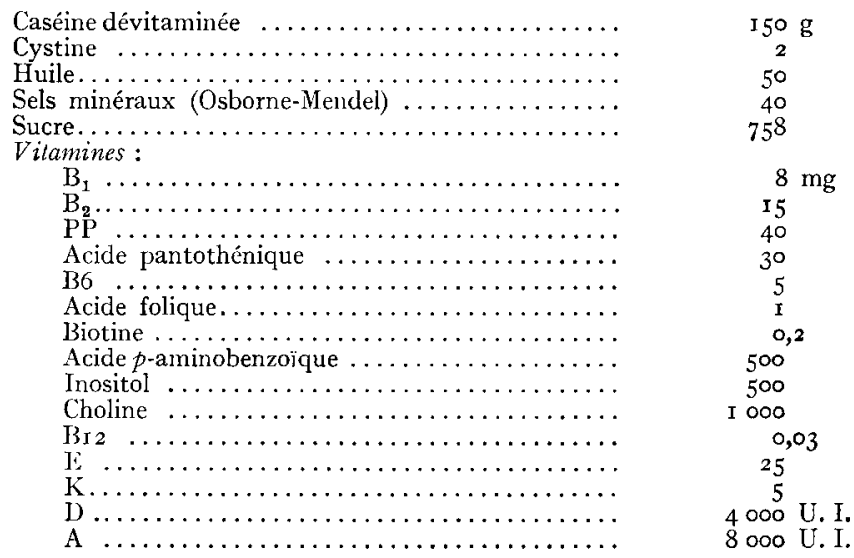

Il faut signaler que pour les dernières vitamines B découvertes, l'omission de la vitamine ne suffit pas à créer l'avitaminose. Dans le cas de la carence du Rat en biotine, par exemple, il faut ajouter au régime une antivitamine, l'avidine, qui bloque la biotine. C'est pourquoi la ration comporte $20 \mathrm{p}$. Ioo de blanc d'œuf cru.

Dans d'autres cas, on additionne la ration de 2 p. Ioo de sulfamides ce qui inhibe les synthèses vitaminiques de la flore intestinale.

Pour le dosage de la vitamine BI2, il faut que les mères des animaux utilisés soient elles-mêmes limitées en cobalamines.

Pour les dosages en acide ascorbique, utilisant obligatoirement le cobaye, la ration carencée est une ration naturelle privée de verdure ; 
elle peut être à base de haricots, de levure et de beurre ( 126 ) ou composée de flocons d'avoine et de poudre de lait chauffé à $I 20^{\circ}\left(I 5^{2}\right)$.

\section{Dosage de la thiamine}

Il existe de nombreuses méthodes biologiques de dosage de cette vitamine. Elles sont spécifiques et ne demandent pas d'hydrolyse particulière de l'échantillon $(33,6 \mathrm{I})$.

L,e régime peut être une ration synthétique privée de thiamine, ou plus simplement une ration naturelle préalablement étuvée 3 heures pour la priver de Br. C'est ainsi que la méthode officielle britannique utilise le mélange suivant, comme régime de base pour le Rat, après chauffage convenable :

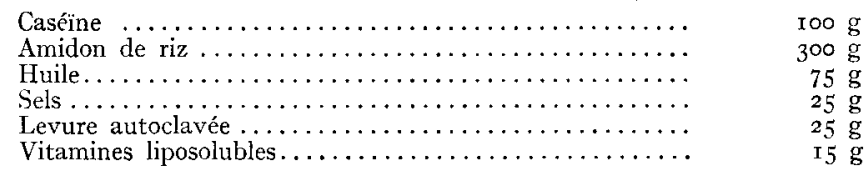

Cette vitamine peut être dosée biologiquement à l'aide du Pigeon, du Poussin ou du Rat.

a) Pigeon.

On utilise la méthode préventive ou curative de la polynévrite du pigeon $(30,32,39,8 \mathbf{I}, 88)$. Dans la deuxième méthode, le test consiste à observer le pourcentage d'oiseaux guéris $(32,88)$.

b) Poussin.

Il existe une méthođe basée sur « l'index de mortalité par polynévrite », exprimé ainsi (84):

durée de l'expérience en jours (22 jours) - nombre de jours de survie.

Il est évident que plus le lot est riche en thiamine, plus la valeur de cet index est faible.

$$
\text { c) Rat. }
$$

On peut utiliser une méthode préventive ou curative, ou encore la mesure de la bradycardie.

I a précision de la méthode préventive est de 1'ordre du $\gamma$ si on donne les échantillons à 3 niveaux différents au moins. La durée de l'essai est passée de 8 semaines (I49) à 4 semaines (3I) et même à ro jours (I45). La prépériode se poursuit jusqu'au moment où la courbe de poids des animaux devient stationnaire (3 semaines).

Dans la méthode curative la prépériode dure 2 mois environ (I56).

On sait, par ailleurs, que le rythme cardiaque du Rat diminue au 
cours de la carence BI et qu'il revient à la normale avec un retour à un régime équilibré, et proportionnellement à la quantité de vitamine offerte à l'animal.

Sur cette observation on a pu établir une méthode de dosage de la thiamine (I3) : après 3 semaines de carence on mesure le rythme cardiaque des animaux à l'aide de l'électrocardiographe. On administre alors des doses connues de vitamine pure ou de solution à titrer et 24 heures après on mesure à nouveau la fréquence cardiaque. I a différence entre 1es 2 valeurs permet de calculer la dose de BI administrée aux animaux.

\section{Dosage de la riboflavine}

On peut utiliser le Poussin $(37,83)$ ou le Rat (I7, I8, 42, 47). Il est préférable d'utiliser le Rat.

Depuis près de 25 ans la vitamine $G$ est dosée par la méthode préventive chez le Rat, et a été nettement améliorée. Mais, comme pour tous ces dosages, il est difficile d'avoir une réponse spécifique et il a été montré que la composition de la ration et de l'échantillon pouvait influencer la croissance de l'animal. C'est principalement la nature et le taux des glucides et des lipides qui peuvent modifier la réponse de l'animal (IO4).

\section{$4^{\circ}$ Dosage de l'acide pantothénique}

Ici non plus, le, dosage n'est pas rigoureux en ce sens que l'on rencontre un certain facteur d'épargne de l'acide pantothénique dans la ration de base ou dans la nature des échantillons (35); on dose plus une efficacité pantothénique que la vitamine elle-même. Par contre, les méthodes biologiques offrent — sur les méthodes microbiologiques l'avantage de pouvoir doser des formes liées de l'acide pantothénique sans hydrolyse préalable $(27,67)$.

Pour ce dosage il est possible d'utiliser le Rat $(4,5,59$, I02), mais la méthode préventive s'étale sur 4 semaines, tandis que les dosages sur Poussins, tout aussi satisfaisants, ne demandent que ro jours (85).

\section{$5^{\circ}$ Dosage de la niacine}

Les dosages biologiques de la niacine présentent d'assez grosses difficultés pour deux raisons : d'abord la plupart des animaux (Rat, Poussin) synthétisent des quantités importantes de niacine et par suite il est difficile d'obtenir des animaux carencés, d'autre part étant donné les interrelations niacine-tryptophane il est impossible de doser des 
échantillons contenant des protéines. Ainsi, ne peut-on appliquer la méthode biologique qu'à des solutions pures de niacine.

Avec de tels échantillons il est possible de pratiquer la méthode préventive chez des Poussins $(26)$, des Rats $(65,95)$ ou de jeunes chiens (I76) sur qui on observe la prévention de la blacktongue.

\section{fo Josage de la vitamine $\mathrm{B6}$}

Le dosage biologique de cette vitamine est difficilement spécifique car la composition de la ration interfère avec la vitamine $(9,38)$; mais l'échantillon peut être fourni directement sans hydrolyse.

On peut employer le test de l'acrodynie (I66) chez le Rat, en sachant que la production et la guérison de ce symptôme ne sont pas sous la seule dépendance de la vitamine $\mathrm{B} 6$, et que son intensité varie avec les saisons (I4, 60, I5I).

La meilleure technique est celle basée sur la croissance du Rat (25, 28 , I42, I43). I,e régime de base peut être le suivant: sucre $75 \mathrm{~g}$, fibrine $\mathrm{I} 8 \mathrm{~g}$, sels $4 \mathrm{~g}$, huile de maïs $3 \mathrm{~g}$ et toutes les vitamines hormis B6.

On peut également doser la vitamine B6 sur le Poussin en pratiquant la méthode préventive (I42) ou curative (II7).

Si l'échantillon est mélangé à la ration du Rat ou du Poussin et donné par conséquent en même temps que celle-ci, le pyridoxal et la pyridoxamine présentent une activité de $25 \mathrm{p}$. Ioo inférieure à celle de la pyriroxine; par contre si l'échantillon est donné per os d'une manière séparée de la ration, ou s'il est sous forme d'une solution injectée intrapéritonéalement, les 3 composés de la famille $\mathrm{B} 6$ offrent une activité comparable. L'activité du pyridoxal et de la pyridoxamine est fonction de la forme sous laquelle ils sont administrés, et ceci explique que les dosages biologiques peuvent donner des résultats plus faibles que les techniques microbiologiques.

I1 existe une larve, Corcyra cephalonica St., dont la croissance est proportionnelle à la quantité de $\mathrm{B} 6$ qu'elle reçoit ; on a utilisé cette propriété à des fins analytiques. Dans ce cas les 3 formes de la vitamine exercent une activité comparable (I40, I4I).

\section{$7^{\circ}$ Dosage de la biotine}

La méthode curative chez le Rat semble spécifique. Après 6 à 8 semaines de préparation les lots sont constitués et le dosage dure 4 semaines au bout desquelles on enregistre les gains de poids.

On peut réaliser le même dosage à l'aide de Poussins ; dans ce cas la prépériode est plus courte (4 semaines).

Si l'on choisit le Rat, le régime de la prépériode doit contenir de 
1'avidine, c'est-à-dire du blanc d'œuf cru. Ceci n'est pas indispensable dans le cas du Poussin $(2,66)$.

Pendant l'essai proprement dit, le blanc d'œuf est remplacé par une protéine dévitaminée, comme la caséine, sinon il bloquerait la biotine ajoutée dans les différents lots.

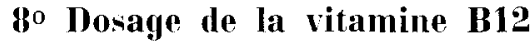

La préparation des animaux est un peu spéciale : non set1ement pendant la prépériode les animaux (Rat ou Poussin) ne doivent pas recevoir de vitamine $\mathrm{B} I 2$, c'est-à-dire que la ration doit être entièrement végétale, à base de soya la plupart du temps (235), mais encore les mères doivent-elles avoir été dans des conditions sous-optimales en ce qui regarde ce facteur.

Pendant la prépériode, on peut accélérer la carence en ajoutant à la ration de 0,06 à $0, \mathrm{I}$ p. Ioo de thyroprotéine (I27).

Dans les dosages à l'aide de Poussins l'essai dure 3 à 4 semaines et le test est le gain de poids (I35).

Avec le Rat (53, Ior) on enregistre également le taux de croissance après une période de 2 à 4 semaines.

\section{9o Dosage de l'acide ascorbique}

Les méthodes biologiques dosent à la fois la forme oxydée et la forme réduite de l'acide ascorbique.

Comme on le sait le Rat synthétise la vitamine $\mathrm{C}$ ce qui oblige à se servir du Cobaye pour les études sur le scorbut.

Dans le dosage de la vitamine $\mathrm{C}$ on utilise done des cobayes que l'on choisit adultes (contrairement à ce qui se passe pour les membres du complexe B il est possible de carencer un animal adulte en acide ascorbique).

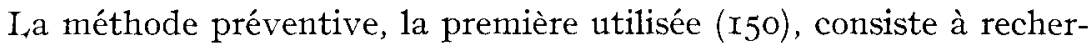
cher la quantité minimum d'échantillon pour prévenir le scorbut. Ia méthode curative s'applique à la restauration des animaux carencés par une prépériode d'une quinzaine de jours. Dans les 2 cas le test est la courbe pondérale des animaux.

Par ailleurs, une des manifestations du scorbut, toujours chez le Cobaye, est utilisée à des fins analytiques. Cette avitaminose modifie nettement l'histologie de la dent :

- désorganisation des odontoblastes ;

- structure irrégulière de la dentine ;

- décalcification de la prédentine. 
On a échafaudé une méthode de dosage basée sur la prévention des troubles scorbutiques de la dent $(73,87)$.

Il est également possible de mesurer 1'intensité de la carence ascorbique en dosant la phosphatase alcaline du sang, dont le taux est proportionnel à la quantité de vitamine chez l'animal (58).

\section{c. - LES MÉTHODES CHIMUUES ET PHYSIQUES}

Dans les méthodes biologiques, une difficulté majeure était d'être assuré que ni la composition de la ration, ni la nature de l'échantillon n'influaient sur la réponse de l'animal. Si ces soucis ne se retrouvent pas dans les méthodes chimiques, celles-ci n'en sont pas pour autant plus spécifiques a priori.

\section{1 o Généralités}

Dans le cas présent, les principes des méthodes sont basées sur une réaction - la plupart du temps colorée - de la molécule vitaminique ; mais dans les échantillons il est rare que d'autres molécules, sans activité vitaminique, ne donnent pas la même réaction que la vitamine. C'est ainsi que les méthodes fluorométriques de dosage de la thiamine et de la riboflavine demandent la plupart du temps une purification de l'extrait pour éliminer des substances à fluorescence parasite. De même dans le dosage de la vitamine $\mathrm{C}$, basé sur le pouvoir réducteur de l'acide ascorbique, il convient d'éliminer ou d'inhiber les autres systèmes oxydoréducteurs de 1'extrait.

C'est pourquoi, dans ces méthodes, ainsi que dans les techniques microbiologiques, la préparation de l'extrait réclame des soins nombreux et attentifs; elle se passe en 2 temps : d'abord hydrolyse de la molécule vitaminique (ce qui n'était pas utile dans les dosages sur animaux), ensuite purification de l'extrait.

L'hydrolyse est simple et fonction des propriétés de la vitamine : si elle est très résistante, comme l'acide nicotinique, la prise sera hydrolysée chimiquement à l'autoclave; par contre, si la molécule est plus fragile, telle la thiamine, l'échantillon subira une légère hydrolyse chimique puis une digestion enzymatique appropriée, c'est-à-dire fonction des liaisons dans lesquelles la molécule est incluse. A ce propos, on peut citer la fonction des principaux enzymes utilisés :

- enzymes protéolytiques : papaïne, pepsine ;

- enzymes phosphorolytiques : takadiastase, mylase $\mathrm{P}$, clarase, polidase $\mathrm{S}$.

- enzymes amylolytiques : clarase, takadiastase, mylase $\mathrm{P}$. 
Ces enzymes sont des produits commerciaux, utilisés aussi bien dans les méthodes chimiques que microbiologiques; ils doivent être à la fois chimiquement et bactériologiquement purs.

Après hydrolyse, l'extrait est purifié, soit par adsorption sur terres ou charbons suivie d'une élution, soit par oxydation, ou autre traitement chimique. Cette opération a pour but de séparer la vitamine des autres corps pouvant donner la même réaction finale, ou de détruire ces corps parasites.

Actuellement on peut employer la chromatographie comme méthode de séparation et de purification de la vitamine à doser : il est possible de travailler à l'aide de chromatogrammes sur papier. Une fois la vitamine isolée on pratique généralement à une réaction colorée (méthodes chimiques) ou bien on soumet les fractions à un test de croissance de microorganisme (méthodes microbiologiques) (I05 $a$ ).

En ce qui concerne le dosage chimique celui-ci se termine généralement par le développement d'une substance colorée ou fluorescente dont on mesure l'intensité à l'aide d'un appareil approprié ; on rapporte la valeur de l'extrait à une courbe-étalon constituée avec une solution pure de vitamine.

Enfin, il faut signaler que si l'acide ascorbique et les vitamines BI et $\mathrm{B} 2$ se dosent couramment par voie chimique, les autres vitamines $\mathrm{B}$ ne le sont qu'exceptionnellement. On préfère les méthodes microbiologiques pour les membres plus récents du complexe $B$.

\section{$2^{\circ}$ Dosage de la thiamine}

La méthode la plus employée est celle qui consiste à doser un produit d'oxydation de la thianime, la thiochrome. Ce corps émet une couleur bleue en lumière ultra-violet.

La réaction a lieu en milieu fortement alcalin par l'action du ferricyanure de potassium (6, I20) ou du permanganate de potassium (79).

Le thiochrome ainsi obtenu est recueilli dans de l'alcool isobutylique.

La sensibilité de cette méthode est de l'ordre de I/ Ioo de $\gamma$.

Cette méthode exige 1'hydrolyse des formes phosphorylées de la thiamine, car le phosphate de thiamine donne un phosphate de thiochrome insoluble dans l'isobutanol.

On peut noter que le $\mathrm{N}$-méthylnicotinamide perturbe la transformation de la thiamine en thiochrome, et que ce dérivé de l'acide nicotinique doit être éliminé par adsorption sur Permutit (II4a).

En pratique, on commence l'hydrolyse de l'échantillon en milieu $\mathrm{SO}^{2} \mathrm{H}_{4} \mathrm{O}, \mathrm{I} \mathrm{N}$ à $\mathrm{IOO}^{\circ}$ ou à l'autoclave. Après refroidissement, on ajoute à $\mathrm{pH} 4,5$ des enzymes phosphorolytiques et autres à raison de $\mathrm{r} /$ ro du poids sec de l'échantillon et on incube une nuit à $45^{\circ}$. 
A ce moment on purifie généralement l'extrait par adsorption sur une colonne de Decalso (68), puis on élue à l'aide d'une solution de chlorure de potassium. On pratique alors l'oxydation de la thiamine en ajoutant de la soude et l'oxydant, et enfin l'isobutanol une minute exactement après la soude. On agite vigoureusement et on centrifuge : le thiochrome passe dans la couche alcoolique.

On mesure la fluorescence du thiochrome, ou bien on peut effectuer une lecture spectrophotométrique de ce dérivé $(55 a)$.

Ce procédé subit quelques exceptions selon la nature de l'échantillon. C'est ainsi que dans le cas du lait on commence par précipiter la caséine par 1'acide trichloracétique, avant de faire la digestion enzymatique.

Pour les dosages dans l'urine, il n'est pas nécessaire de pratiquer d'hydrolyse, mais comme l'urine renferme des substances fluorescentes, il est indispensable de pratiquer une purification. Cette opération a fait l'objet de nombreuses études critiques et on y a apporté des solutions diverses (80, I2I, I30).

Le sang offre également un cas particulier, en ce sens que l'hématine favorise la destruction du thiochrome. Pour éviter ce phénomène on procède au traitement suivant ( $\mathrm{x} 8$ ) : hydrolyse rapide du sang en milieu acétique, puis digestion enzymatique ordinaire. On traite ensuite par l'acide trichloracétique.

Il existe évidemment de très nombreuses variations de cette technique et aussi d'autres principes de méthodes. En particulier, une méthode de dosage pour le sang (23) est basée sur la réaction de la thiamine sur une amine aromatique ( $p$-aminoacétophénone) (I07, I22) qui donne un produit coloré.

\section{$3^{0}$ Dosage de la riboflavine}

Il existe 2 principes chimiques permettant de mesurer fluorimétriquement la riboflavine : soit on dose directement la molécule de la riboflavine, soit on dose un dérivé de cette vitamine qui est aussi fluorescent, 1a lumiflavine.

Ce second procédé $(54,82$, I29, I34) consiste à irradier la riboflavine en milieu alcalin pour obtenir la lumiflavine. On pratique une hydrolyse acide, ensuite on photolyse la vitamine $\mathrm{B} 2$ à $\mathrm{pH} \mathrm{I}_{3}$ ou I4; on acidifie et on extrait la lumiflavine par le chloroforme. La solution chloroformique est passée au fluorimètre.

Cette méthode de dosage est sujette à de très graves reproches car on ne mesure parfois guère plus de la moitié de la riboflavine de l'extrait sous forme de lumiflavine (I03). La transformation de la riboflavine en lumiflavine, apparaît rarement quantitative. 
C'est pourquoi, la méthode à recommander est le dosage de la fluorescence de la riboflavine elle-même.

L'hydrolyse de l'échantillon se fait par voie chimique (ClH o, I N) ou enzymatique (takadiastase et papaïne) ou par les deux moyens à la fois $(93, I I 3, I 78)$.

La purification de l'extrait peut se faire de diverses façons :

- soit on oxyde rapidement l'extrait avec du permanganate $(2 \mathrm{mi}$ nutes) et on élimine le surplus avec de l'eau oxygénée (93). Ce traitement peut créer une certaine fluorescence (89), et, en présence d'une forte quantité de fer, il peut se produire une oxydation de la riboflavine (99) ;

- soit on peut adsorber la riboflavine sur une terre, tel que le Florisil et l'éluer ensuite par une solution acétique de pyridine $(29,49,72)$.

Il semble préférable de faire ces 2 traitements à la suite en commençant par 1'oxydation de l'extrait ;

- soit la séparation entre la riboflavine et les autres pigments peut s'opérer par réduction avec l'hydrosulfite ou le chlorure stanneux ( $7 \mathrm{I}$, 136). Seule la riboflavine se réoxyde à l'air. Cette séparation se fait au moment du titrage ;

- soit après l'oxydation par le permanganate, on peut extraire la riboflavine en la faisant passer dans un mélange pyridine-butanol. Pour terminer on titre la solution de riboflavine dans un fluorimètre, et on mesure la fluorescence verte de la riboflavine.

Il faut noter que pendant la purification de l'urine en vue du dosage de la vitamine $B 2$, il apparaît des corps présentant des réactions analogues à celles de la riboflavine.

Enfin, il existe d'autres méthodes chimiques de dosage de la vitamine $\mathrm{B} 2$, notamment une microméthode fluorométrique (22) et des méthodes permettant de dissocier la riboflavine libre de la B2 estérifiée et de la B2 des nucléotides (I0, 44, 54).

\section{$4^{0}$ Dosage de la niacine}

Ce facteur est le dernier des membres du complexe $B$ à être dosé d'une manière habituelle par voie chimique. Il existe un grand nombre de méthodes de dosage de la niacine. Cette vitamine étant un dérivé de la pyridine, les méthodes de dosage seront des réactions colorées du noyau pyridique.

La plus connue est celle basée sur la réaction de KoENIG (9I, I82) condensation du bromure de cyanogène sur la pyridine, ce qui donne un sel de pyridinium. Ce produit de condensation donne ensuite naissance à un dérivé d'aldehyde glutaconique, qui est de couleur rouge dans le cas de la vitamine PP. Cette coloration est due à l'action d'une amine aromatique. 
Pour obtenir des résultats valables, il faut que toute l'amide soit transformée en acide nicotinique pendant l'hydrolyse.

Par ailleurs, les conditions expérimentales du dosage, et notamment le choix de l'amine aromatique, ont fait l'objet de nombreuses publications dont les dernières en date sont celles de GyorgY et coll. (6I) et de FrIEDMANN et coll. (52). En général, le choix de l'amine s'est porté sur la $p$ amino acétophénone. La trigonelline ne donne pas la réaction de KOENIG (I75).

Il existe de nombreuses autres méthodes chimiques de dosage de la vitamine $P P$, nous n'en parlerons pas étant donné leur utilisation limitée.

\section{Dosage de la N' méthylnieotinamide}

Chez l'Homme, le Chien ou le Porc le principal métabolite urinaire de la niacine est la $\mathrm{N}^{\prime}$ méthylnicotinamide. Chez les Mammifères on rencontre de la trigonelline. Ces deux dérivés se dosent globalement selon une technique de HuFF et coll. (74). Elle consiste à traiter les métabolites de 1'acide nicotinique par l'acétone en milieu alcalin. Il se développe alors une fluorescence que l'on rapporte à celle d'une solution connue de $\mathrm{N}^{\prime}$ méthylnicotinamide.

Il est conseillé de décolorer d'abord les urines sur du charbon actif en milieu acétique, afin d'éliminer l'interférence de certains pigments urinaires.

La trigonelline peut aussi se doser dans les urines de mammifères (4I, 5I, I38).

\section{5o Dosage de l'acide pantothénique}

Cette vitamine ne se dose pratiquement pas par voie chimique. Les méthodes qu'on a proposées s'appliquent plutôt à des solutions pures qu'à des extraits de nature complexe.

Les principes sur lesquels sont bâtis les dosages sont ou la libération par hydrolyse chimique de l'alanine, et son dosage colorimétrique (34, I69), ou la libération de 1'acide pantoïque et son dosage (I8I) ; cette dernière méthode ne différenciant pas l'acide pantothénique de sa moitié inactive, la lactone.

Une méthode chromatographique vient d'être avancée : on sépare cette vitamine par adsorption sur le Florisil et ensuite le sulfate de cuivre donne une réaction colorée caractéristique (I $7 \mathrm{I})$. 


\section{$6^{\circ}$ Dosage de la vitamine B6}

Comme dans le cas de la niacine, il existe de nombreuses méthodes chimiques pour doser la vitamine $B 6$, mais une se détache particulièrement : celle de GrbBs (56) utilisant le dichloro 2-6 quinonechlorimide.

On peut faire à l'ensemble de ces méthodes le reproche d'avoir été étudiées au moment où l'on ne connaissait que le chlorhydrate de pyridoxine et non le pyridoxal et la pyridoxamine, et par suite ces techniques rendent compte asse $z$ mal des 2 derniers membres de la famille de la vitamine B6. Par ailleurs, malgré une certaine analogie de structure, les réactions de dosage de la pyridoxine ne sont pas sensibles à la niacine présente dans l'extrait (96).

La réaction de l'adermine avec le dichloro 2-6 quinone chlorimide donne une coloration bleue (I48) qui permet de doser $0,5 \%$ par cc. Une solution alcool-butanol à $\mathrm{pH} 7,0$ permet d'éliminer certaines substances interférantes.

Autrefois on déterminait un "blanc" avec un tampon de borate, qui bloque la pyridoxine; sur cette solution on fait agir le chlorimide qui donne une coloration uniquement avec les substances parasites. Parallèlement, si on fait agir le chlorimide sans tampon de borate, on obtient la valeur de la pyridoxine plus celle des autres corps. Par différence, il en découle la teneur de l'extrait en pyridoxine.

Ce procédé est périmé aujourd'hui car on s'est aperçu que le pyridoxal et la pyridoxamine réagissent avec le chlorimide même en présence de borate; c'est pourquoi le tampon de borate peut maintenant servir à séparer la pyridoxine d'un côté, le pyridoxal et la pyridoxine d'un autre côté.

En pratique, on commence par hydrolyser la vitamine avec de l'acide sulfurique et ensuite avec de la takadiastase. A ce moment on adsorbe la pyridoxine sur du Superfiltrol à pH 3,0, puis on élue par une solution de dichloro 2-6 quinone chlorimide dans le butanol (II). On ajoute enfin une solution de véronal à $\mathrm{pH} 7,8$ pour développer la coloration (I6).

Une variante fait réagir la pyridoxine dans le chlorimide dans l'isobutanol. On élimine les interférences (bases et sels) avec un tampon vigoureux ammoniaque-chlorure d'ammonium. La coloration maximum se produit en une minute. Dans ce cas, le pyridoxal et la pyridoxamine réagissent faiblement par rapport à la pyridoxine (ro8).

Une méthode basée sur une réaction entre 1'acide sulfanilique diazoté et l'adermine dose un composé azoïque jaune-rouge (I67). L'inconvénient de la méthode est que la pyridoxine donne une coloration rouge-orange, la pyridoxamine une coloration orange-rose et le pyridoxal une coloration jaune brillante (II6). De plus, dans ce dosage, il faut éli- 
miner tous les composés azotés : protéines, purines, pyrimidines, etc. (I68). On peut adsorber la vitamine sur le Superfiltrol, et l'éluer ensuite par l'alcool en milieu alcalin.

\section{$7^{\circ}$ Dosage de l'acide folique}

Cette vitamine peut se doser chimiquement de deux façons. Ia méthode de Hutchings et coll. (75) consiste à réduire l'acide folique par le zinc en milieu chlorhydrique $\mathrm{N} / 2$, ce qui donne une ptéridine et une amine aromatique, dosée colorimétriquement (20). On peut diminuer l'interférence de certains corps par une réduction avec le chlorure stanneux (57) en remplacement du zinc.

Une microméthode, basée sur l'oxydation de l'acide folique par le permanganate en milieu alcalin, donne 1'acide amino-2-hydroxyptéridine-4 carboxylique qui est dosé fluorométriquement après purification sur le Florisil (I).

\section{go Dosage de la biotine}

A notre connaissance il n'existe pas de méthode chimique pour doser la biotine.

\section{go bosage de la vitamine $B_{12}$}

La vitamine BI2 est dosée chimiquement d'une manière peu usitée.

En photolysant de la vitamine $\mathrm{BI} 2$ avec ane lumière monochromatique le groupe cyanogène de la molécule est libéré. On peut l'entraîner par un courant d'air et ainsi le doser colorimétriquement à l'aide du phosphate de chloramine 'T (I9).

\section{Dosage de l'acide ascorbique}

La méthode chimique est la seule technique couramment employée pour le dosage de l'acide ascorbique. Ce corps réduit nombre de réactifs, et pour la détermination quantitative de l'acide ascorbique on utilise généralement son pouvoir de transformer un colorant en son leucodérivé.

La technique la plus répandue consiste à observer la décoloration du dichloro 2-6 phénolindophénol (I73) qui est un colorant rouge ou bleu selon le $\mathrm{pH}$.

Il convient de prendre certaines précautions car le dichloro-2-6 phénol indiphénol peut oxyder des substances organiques très variées $(7,40,43,46,55,128$, I80). 
En pratique, on extrait l'acide ascorbique de l'échantillon à l'aide de l'acide trichloracétique, acétique, métaphosphorique, oxalique, etc.

Si l'on veut doser l'acide ascorbique total il faut passer l'extrait à un courant de $\mathrm{SH}_{2}$ en milieu acide pour réduire la forme déhydroascorbique.

Ensuite, on mesure au photomètre, toutes les I5 ou 30 secondes, 1a décoloration d'une solution à $0,025 \mathrm{p}$. Ioo de dichloro $2-6$ phénolindophénol par action de l'extrait contenant l'acide ascorbique (I06, Iog).

Une autre méthode d'éffectue à $\mathrm{pH} 3,0$ et, en présence, d'hyposulfite on éclaire violemment la solution de bleu de méthylène contenant1'extrait d'acide ascorbique.

On peut doser la somme acide ascorbique plus acide déhydroascorbique par une réaction avec la dinitro-2-4 phénylhydrazine, qui donne une osazone de couleur rouge (I33) et dont on dose l'intensité au photomètre.

Enfin, il est possible de doser chromatographiquement la vitamine $\mathrm{C}$ sur papier en faisant un chromatogramme de la dinitro 2-4 phénylhydrazone de l'acide ascorbique, que l'on dose colorimétriquement après élution (II7 $a$ ); une autre méthode chromatographique sépare l'acide ascorbique de l'acide isoascorbique et d'autres substances perturbantes $(67 a)$.

\section{D. — LES METHODES MICROBIOLOGIQUES}

Peu avant la dernière guerre SchopPen et coll. (I44) ont montré qu'un champignon mycelien, Phycomyces blakesleanus, avait une croissance proportionnelle à la quantité de thiamine contenue dans son milieu de croissance. Une telle observation, reproduite sur d'autres moisissures, puis sur des bacilles, et pour tous les membres du complexe $B$, est à la base de la technique microbiologique pour le dosage des vitamines $B$ et des acides aminés indispensables.

$\mathrm{L}_{\mathrm{a}}$ vitamine $\mathrm{C}$ ne se dose pas microbiologiquement.

\section{Généralités}

Cette technique a pris un essor remarquable, et qui semble dû à deux sortes de raisons : les unes scientifiques, les autres matérielles.

Lorsqu'il est apparu que l'efficacité vitaminique était due à la présence d'une vitamine et de corps à activité vitaminique, ainsi que d'éventuelles antivitamines, les dosages chimiques se sont révélés dépassés. Au contraire, la croissance d'un microorganisme présentait les mêmes avantages que les anciennes méthodes sur animaux supérieurs en ce qui concerne l'efficacité vitaminique des échantillons. 
Ces méthodes microbiologiques offrent 1'avantage, sur les techniques biologiques, d'être rigoureusement spécifiques, en ce sens qu'aucun des membres du complexe B n'influence la pousse d'une souche se développant dans les conditions du dosage. SNELL et STrong (I59) ont pris des tubes de courbe-étalon d'un dosage de B2, contenant tous $0, \mathrm{I} \gamma$ de riboflavine, c'est-à-dire un point correspondant au début de la courbe. Ces tubes, dosés au photomètre donnaient des valeurs se situant entre 0,52 et 0,53 . A ces tubes, les auteurs ont ajouté des doses croissantes de vitamines $B$ diverses et ils ont mesuré la croissance de ces tubes au photomètre, ce qui a donné les résultats suivants, mettant en évidence la spécificité des dosages microbiologiques :

\begin{tabular}{|c|c|c|c|c|c|c|}
\hline \multirow{2}{*}{$\mathrm{B} 2$ seule $\mathrm{O}, \mathrm{I} Y$} & \multirow{2}{*}{$\begin{array}{c}\text { Quantité de } \\
\text { vitamine ajoutée }\end{array}$} & \multicolumn{5}{|c|}{ Vitamine ajoutée, et lecture des tubes au photomètre } \\
\hline & & Thiamine & Pyridoxine & Niacine & Ac. Panto. & Ac. Ascor. \\
\hline $0,5^{2}$ & $\mathrm{o}, \mathrm{I} \mathrm{mg}$ & 0,55 & 0,53 & $0,5^{2}$ & 0,54 & 0,54 \\
\hline 0,52 & I & 0,52 & 0,55 & $0,5 \mathrm{r}$ & $0,5^{1}$ & $0,5^{2}$ \\
\hline 0,53 & Io & 0,53 & 0,54 & 0,53 & 0,53 & 0,49 \\
\hline 0,52 & 100 & 0,52 & 0,53 & 0,53 & 0,53 & 0,54 \\
\hline 0,53 & I 000 & 0,53 & 0,53 & 0,52 & 0,53 & 0,57 \\
\hline
\end{tabular}

Par ailleurs, lorsque la technique microbiologique est utilisée pour la détermination d'un des membres du complexe $B$, le dosage d'autres vitamines ne demande pas un effort supplémentaire considérable, car il est possible de se servir d'une même solution pour doser un grand nombre de vitamines. C'est ainsi que l'on peut mener " de front " le dosage des principaux membres du groupe $B$.

Cette technique comprend deux parties préparatoires : l'extraction de la vitamine et la composition du milieu de base.

L'extraction de la vitamine se fait par hydrolyse, d'une manière souvent identique à l'hydrolyse effectuée pour un dosage chimique : autoclavage poussé si on en a la possibilité, hydrolyse enzymatique si 1a vitamine est sensible.

I. volume de liquide de l'extrait doit être au minimum dans un rapport de 5 à I avec le poids de l'échantillon, et il est conseillé de suspendre la prise dans dix fois son poids de liquide. L'hydrolyse chimique a intérêt à être faite en milieu chlorhydrique plutôt que sulfurique, l'anion $\mathrm{SO}^{4}$ présentant une toxicité possible pour le microorganisme.

La purification de l'extrait est très simple en microbiologie: seules les protéines et les lipides sont à éliminer : les premières sont extraites par une filtration à $\mathrm{pH} 4,5$ en fin d'hydrolyse, c'est-à-dire une fois la vitamine libérée des liens protidiques dans lesquels elle peut être incluse ; les lipides peuvent être éliminés grossièrement par un traitement à froid à $\mathrm{pH} 4,5$ de préférence avec le mélange $2 / 3$ éther sulfurique $\mathrm{I} / 3$ éther de pétrole. Cette opération se fait avant ou après 1'hydrolyse. 
Cette double élimination des protéines et des lipides est rigoureusement indispensable. Nous n'en prendrons à témoin que le dosage de la riboflavine effectué par $L$. casei $\varepsilon$. Dans le cas d'échantillons riches en protéines, l'élimination des matières azotées se traduit de la manière suivante (I79) :

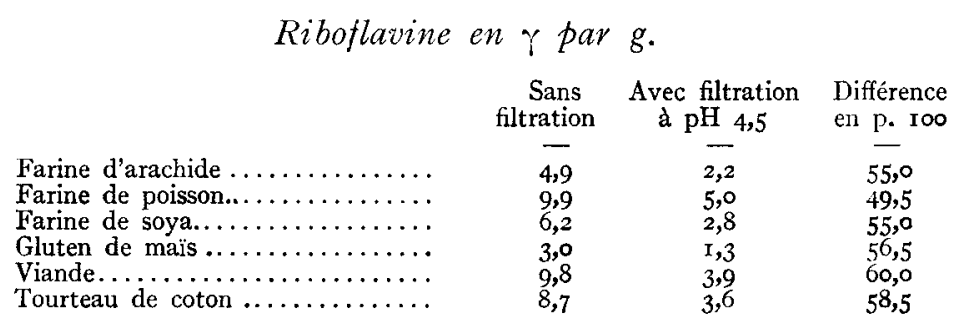

Dans ces quelques chiffres on voit que la présence de protéines dans l'extrait fournit des taux de riboflavine deux fois trop élevés. L'influence des lipides, parfois moins nette, représente également une cause d'erreur très appréciable, ces chiffres le prouveront (8) :

\begin{tabular}{|c|c|c|c|}
\hline & $\begin{array}{l}\text { Sans } \\
\text { traitement } \\
-\end{array}$ & $\begin{array}{l}\text { Traité par } \\
\text { l'éther }\end{array}$ & $\begin{array}{l}\text { Différence } \\
\text { en p. I00 }\end{array}$ \\
\hline arine de foie & $5^{6, \mathrm{I}}$ & 34,0 & 40,0 \\
\hline Farine de foie.... & 83,5 & 42,2 & 49,5 \\
\hline Farine de luzerne $\ldots \ldots \ldots \ldots \ldots$ & 14,4 & 13,6 & 7,0 \\
\hline Farine de déchets de viande....... & 8,7 & 5,4 & 38,0 \\
\hline Farine de poisson...... & 7,0 & 5,2 & 25,5 \\
\hline Solubles de distiller & 22,0 & 16,9 & 23,0 \\
\hline
\end{tabular}

On peut démontrer l'action de facteur de croissance des lipides en ajoutant à des échantillons des acides gras variés : dans ce cas, 1a pousse du lactobacille est généralement stimulée et on trouve des valeurs généralement comparables à celles obtenues sans extraction à l'éther. Néanmoins il faut signaler que certains acides gras peuvent, selon leur concentration, jouer le rôle de facteur de croissance ou, au contraire, inhiber partiellement la pousse microbienne. Par la double élimination des protéines et des lipides de l'extrait on obtient alors une valeur qui correspond spécifiquement à la teneur vitaminique de l'extrait. En effet, comme nous l'avons montré aucune vitamine B n'influe sur la croissance d'une souche quand on se place dans les conditions requises pour l'ana1 yse.

Ces conditions exigent notamment que le milieu de base apporte tous les métabolites nécessaires ou utiles (indispensables ou accessoires) à la croissance de la souche, et cela en quantités supérieures à la dose minimum indispensable au développement. Il est évident que seul le facteur faisant l'objet du dosage doit être totalement absent du milieu de base. 
Ce milieu peut être ou naturel ou synthétique, cette alternative étant fonction de notre propre connaissance des besoins nutritifs des microorganismes. Dans le second cas, il n'y a aucune difficulté à composer le milieu nutritif qui consiste en une liste de produits biochimiques simples.

S'il s'agit d'un milieu naturel, on part toujours de substances complexes (levure, peptone) dont on doit éliminer la vitamine que l'on veut doser. Pour ce faire il existe des traitements propres à chaque cas qui permettent de détruire spécifiquement tel ou tel facteur de ces milieux naturels. Par exemple, pour le dosage de l'acide pantothénique on élimine cette vitamine de la peptone par l'influence du $\mathrm{pH}$ alcalin à froid : ceci probablement détruit d'autres facteurs sensibles aux bases. Mais pour éliminer l'acide pantothénique de la levure on autoclave celle-ci ce qui détruit des facteurs thermolabiles, dont l'acide pantothénique. Au total, le seul facteur qui sera détruit à la fois dans la levure et la peptone sera 1'acide pantothénique. A titre indicatif, voici les milieux complets pour deux lactobacilles très employés dans les dosages microbiologiques pour cent tubes :

\section{Milieu pour L. Arabinosus I7/5.}

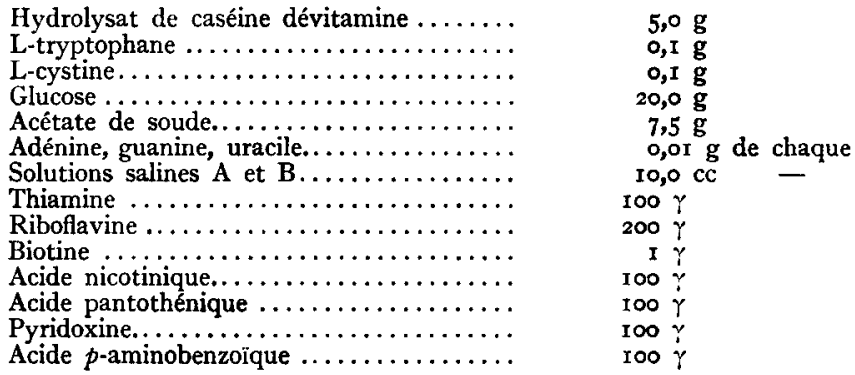

Le milieu est neutralisé à $\mathrm{pH} 7,0$ (bleu de bromothymol) et ajusté à $\mathrm{x} 000 \mathrm{cc}$.

Milien pour L. Casei $\varepsilon$.

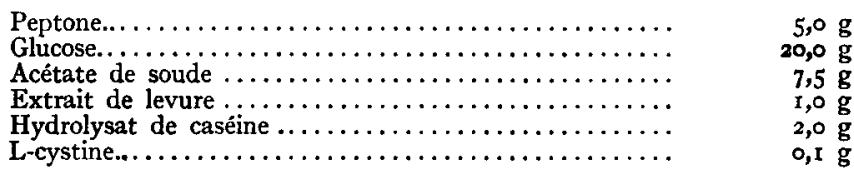

Le milieu est neutralisé à pH 7,0 (bleu de bromothymol) et ajusté à I $000 \mathrm{cc}$.

On peut procéder de deux manières pour remplir les tubes, mais il faut dans les deux cas que le tube renferme les mêmes quantités absolues de milieu et de vitamine : la manière la plus simple est d'utiliser des solutions étalons et des extraits suffisamment concentrés pour que les quantités à utiliser ne dépassent pas $0,5 \mathrm{cc}$ (pipettes au r/Ioo de cc) ; 
on met ensuite ro $\mathrm{cc}^{1}$ du milieu de base dilué selon les indications ci-dessus.

Ensuite, on stérilise, on ensemence avec la souche adéquate, on incube $24 \mathrm{~h}$., ou, de 48 à $72 \mathrm{~h}$. Dans le premier cas on titre néphélométriquement, dans le second on dose l'acide lactique formé dans les cultures de Lactobacilles (avec $\mathrm{Na} O H$ N/Io en présence de bleu de bromothymol).

Comme dans les méthodes chimiques ou biologiques, chaque dosage microbiologique comprend une courbe-étalon. Ici elle est composée de Io points et on prend 4 points croissants par extrait.

Les principales souches employées actuellement sont des bacilles, bien que les premières méthodes aient utilisé des mycéliums.

Les souches doivent être définies avec rigueur et voici leur dénomination exacte avec la référence de l'American Type. Culture Collections (Georgetown University Medical School, Washington DC).

Souches
-

\section{2o Dosage de la thiamine}

En marge des techniques microbiologiques courantes, on peut doser la vitamine BI en mesurant 1'intensité fermentaire de Saccharomyces cerevisiae (levure de boulangerie). En effet, le pouvoir de fermentation de cette souche est lié à la quantité de thiamine présente dans le milieu (I46, I47).

Il existe deux méthodes indirectes pour mesurer l'activité fermentaire de la levure de boulangerie : soit on peut doser l'alcool formé au cours de la fermentation (JAcQuot et ThIVOLLE, 78 ), soit on mesure le gaz carbonique dégagé (Y. ARMAND, 78), en se servant d'un Warburg.

Quelle que soit la méthode adoptée, on constitue une courbe-étalon avec des doses croissantes de thiamine pure, et pour chaque échantillon, on prend plusieurs doses croissantes.

De plus, on traite une partie aliquote de l'extrait par une solution à $o, 6 \mathrm{p}$. Ioo de sulfite acide, et on neutralise ensuite l'excès de sulfite par la quantité exacte d'eau oxygénée nécessaire. Ce traitement a pour but de pouvoir mesurer l'activité de substances interférentes parasites qui augmente le taux de fermentation de la levure. Le sulfite, en effet, dé- 
truit spécifiquement la thiamine en la scindant en pyrimidine et en thiazole qui sont inactifs, mais il respecte les autres facteurs de l'échantillon.

Dans les fioles de Warburg l'incubation se poursuit généralement pendant $3 \mathrm{~h}$ et on mesure les volumes gazeux produits. Pour obtenir la teneur de l'extrait en thiamine, on déduit de la valeur de l'échantillon total le chiffre obtenu avec l'extrait traité au sulfite et on rapporte à la courbe-étalon le produit de la différence.

La méthode la plus courante pour le dosage de la thiamine (I39) utilise le Lactobacillus fermenti 36 .

Ie milieu de base est semi-synthétique. L'incubation dure $\mathrm{I} 8 \mathrm{~h}$ au bout desquelles on titre la néphélométrie des tubes de culture. On peut ainsi doser $5,0 \mathrm{~m} \gamma$ de thiamine.

Rappelons que la première méthode microbiologique a été créée par SCHOPFER et JUNG (I44) pour doser la thiamine à l'aide d'un Phycomyces se développant sur un milieu extrêmement simple.

L'extraction de la thiamine en vue de son dosage microbiologique se fait généralement en deux temps : extraction chimique en milieu sulfurique $0, \mathrm{I} \mathrm{N}$, puis digestion enzymatique (papaïne et clarase) à $\mathrm{pH} 4,5$. Filtration et $\mathrm{pH} 6, \mathrm{o}$ environ.

\section{$3^{\text {o }}$ Dosage de la riboflavine}

Ce facteur se dose habituellement à l'aide de L. caséi \& (I58). Le milieu est un ensemble de produits naturels que l'on prive de riboflavine : caline.

- la vitamine B2 est éliminée de la peptone par photolyse al-

- elle est enlevée de la levure par traitement avec une solution alcaline d'acétate basique de plomb dont on se débarrasse par un passage à $\mathrm{SH}_{2}$.

L'extraction de cette vitamine est sensiblement pareille que celle de la thiamine : rapide autoclavage en milieu $\mathrm{ClH}$ o, $\mathrm{I}$, puis digestion enzymatique (takadiastase et papaïne) à $\mathrm{pH} 4,5$. Filtration et neutralisation à $\mathrm{pH} 7,0$.

$\mathrm{L}_{\mathrm{a}}$ filtration à $\mathrm{pH} 4,5$ est particulièrement recommandée dans ce dosage ainsi que l'extraction des lipides à ce même $\mathrm{pH}$ (I63). Dans les analyses d'urine, l'urée peut jouter le rôle d'inhibiteur, et $20 \mathrm{mg}$ par tube est le taux maximum compatible avec la technique microbiologique (77).

Cette méthode avec $L$. casei permet de doser jusqu'à $50 \mathrm{~m} \gamma$ par cc, mais il est possible de déterminer des concentrations beaucoup plus faibles de riboflavine en utilisant Leuconostoc mesenteroides (ATCC roIoo) qui est sensible à $\mathrm{r}, \mathrm{o} \mathrm{m}_{\Upsilon}$ par cc d'extrait (92). 


\section{$\mathbf{p}^{\circ}$ Dosage de la niacine}

La méthode usuelle est celle de KREHL et coll. (94) basée sur la croissance du L. arabinosus $17 / 5$. Le milieu de base est entièrement synthétique et ne pose pas de difficultés si les produits employés sont suffisamment purs.

Cette méthode dose jusqu'à $50 \mathrm{~m} \gamma$ par cc. d'extrait.

La niacine est suffisamment résistante aux bases ou aux acides pour être entièrement extraite par voie chimique à l'autoclave. Pour beaucoup de types d'échantillons un traitement de 30 minutes à $120^{\circ}$ en milieu $\mathrm{ClH} N$ donne un résultat comparable au même traitement en milieu $\mathrm{NaOH} \mathrm{N}$.

On amène ensuite le $\mathrm{pH}$ à 4,5 , on filtre et 1'extrait est neutralisé. Il est préférable de faire l'hydrolyse en milieu acide, la filtration à $\mathrm{pH} 4,5$ s'en trouvant facilitée.

Il est également possible d'isoler l'acide nicotinique chromatographiquement sur papier, et de faire à ce moment-là un test microbiologique pour mesurer la vitamine PP $(98 a)$.

\section{$5^{\circ}$ Dosage de l'acide pantothénique}

Il existe deux techniques courantes pour doser ce facteur :

- la première utilise $L$. arabinosus $17 / 5(69,154)$ dont le milieu est synthétique,

- la seconde emploie $L$. casei $i$ (Irg) dont le milieu est naturel. L'acide pantothénique est enlevé de la peptone par traitement alcalin à froid, on l'élimine de la levure en faisant alterner les autoclavages en milieu alcalin et en milieu neutre.

Personnellement nous optons pour la deuxième technique qui s'est révélée plus reproductible.

Ces deux méthodes offrent la même sensibilité : ro m $\gamma$ par cc d'extrait. On titre dans les deux cas l'acide lactique formé.

L'extraction de cette vitamine ne peut se faire en milieu acide ou alcalin. Après un rapide autoclavage à $\mathrm{pH}$ légèrement acide, on pratique une digestion enzymatique (mylase $\mathrm{P})$ à $\mathrm{pH} 4,5(23 a)$. Ensuite filtration et neutralisation de 1'extrait.

Telle était 1'hydrolyse classique jusqu'à ces dernières années. Depuis, on a proposé des hydrolyses effectuées à l'aide d'enzymes variés (II5, I 48 a) ou l'autolyse (IOO, IO5) comme procédés d'hydrolyse. Ces modifications font apparaître des quantités plus ou moins importantes d'acide pantothénique par rapport aux valeurs obtenues avec l'hydrolyse par la mylase $P$. 


\section{(60 Dosage de la vitamine $\mathrm{Bb}$}

Une méthode utilisant une levure (Saccharomyces carlsbergensis ATCC No 4228) permet de doser les trois membres de la famille B6, la pyridoxine, le pyridoxal et la pyridoxamine possédant une activité égale vis-à-vis de cet organisme (3).

$\mathrm{I}_{4} \mathrm{e}$ milieu est beaucoup plus simple que ceux destinés aux lactobacilles. On mesure la néphélométrie de ces cultures après $I 8 \mathrm{~h}$ d'incubation.

Une autre méthode permet de doser le pyridoxal et la pyridoxamine (I23) en employant le Streptococcus faecalis $R$. (ATCC No 8043). La pyridoxine est sans activité pour cette souche. Ce microorganisme utilise un milieu synthétique voisin de celui de $L$. arabinosus, et on titre la néphélométrie des tubes après incubation. On peut également doser le pyridoxal à 1 'aide de $L$. casei (I96).

L'extraction de la vitamine $\mathrm{B} 6$ se fait généralement en milieu sulfurique $0,055 \mathrm{~N}$ pendant $\mathrm{I} h$ à l'autoclave. Si l'échantillon est un liquide on ajuste son $\mathrm{pH}$ à $\mathrm{I}, 8-\mathrm{I}, 7$ avec de 1 'acide sulfurique (3) ; il est également possible d'extraire la pyridoxine par $\mathrm{SO}_{4} \mathrm{H}_{2} 2 \mathrm{~N}$ (I62).

On peut aussi utiliser un Neuropora sitophila pour le dosage de la pyridoxine (I62), mais cette souche peut synthétiser la vitamine B6 à partir de certains éléments azotés (I6I).

Par ailleurs, pour $S$. carlbergensis et $N$. sitophila la thiamine est un facteur de croissance ou un inhibiteur. Pour les dosages utilisant $S$. carlbergensis, il faut que la concentration en thiamine soit supérieure à un seuil donné (I25); avec Neurospora on procède à une destruction de la thiamine par un traitement au sulfite qui respecte la pyridoxine.

\section{$7^{\circ}$ Dosage de l'acide folique}

Deux méthodes microbiologiques classiques permettent 1a détermination de 1'acide ptéroylglutamique.

Une technique employant Streptococcus faecalis $R$. fait appel à un milieu synthétique $(36$, II 2$)$ dans lequel on a proposé d'ajouter les purines afin d'obtenir une croissance maximum (I57).

Un autre procédé utilise $L$. casei et un milieu naturel (I3I).

Dans ce cas, on doit éliminer l'acide folique d'un hydrolysat de caséine à l'aide de charbon actif. Cette méthode est la plus sensible : elle détermine des concentrations de $0, I \mathrm{~m} \gamma$ par cc d'extrait.

Dans la première technique on mesure la néphélométrie des tubes, dans la seconde on titre l'acide lactique formé.

L'extraction de 1'acide folique est assez délicate car 1'hydrolyse demande une $\mathrm{Bc}$ conjugase. On en trouve dans des préparations de rein de porc (I5) ou de pancréas de poulet (98).

La digestion enzymatique s'effectue selon le mode habituel. 


\section{go $^{\circ}$ Dosage de la biotine}

Plusieurs méthodes permettent de doser ce facteur, mais une des plus courantes utilise L. arabinosus 17/5 (I60). On emploie un milieu synthétique, et on dose ainsi des extraits ayant des concentrations de $0,2 \mathrm{~m} \gamma$ par cc.

Cette méthode est intéressante dans le dosage du blanc d'œuf, car $L$. arabinosus ne peut pas utiliser la biotine combinée à l'avidine. $L$. casei, au contraire, offre la particularité de pouvoir hydrolyser le complexe biotine-avidine. Mais ce dernier microorganisme demande un milieu plus complexe dont on est obligé de retirer la biotine par action de l'eau oxygénée et par adsorption sur le charbon actif (I53).

Avec les deux méthodes le test est la titration de l'acide lactique.

L'extraction de la biotine est très simple dans le cas de 1'œuf, qui demande seulement un autoclavage à l'eau. Dans l'immense majorité des cas, il faut hydrolyser une heure à $120^{\circ}$ en milieu $\mathrm{SO}_{4} \mathrm{H}_{2} 6 \mathrm{~N}$. On élimine ensuite cet acide sous forme de sulfate de baryum (neutralisation vers $\mathrm{pH} 5,3$ ). On filtre et on neutralise l'extrait.

\section{9o Dosage de la vitamine B12}

Les techniques microbiologiques du dosage de la vitamine BI2 sont très nombreuses et emploient diverses souches dont les plus fréquemment utilisées sont Lactobacillus lactis Dorner (ATCC No 8 ooo), Lactobacillus leichmannii (ATCC ${ }^{0}{ }^{3} \mathrm{I} 8$ et 497) et Escherichia coli $\mathrm{II} 3 / 3$.

Les milieux sont généralement plus simples que ceux utilisés pour les Lactobacilles ordinaires.

On titre généralement la néphélométrie obtenue après une vingtaine d'heures d'incubation.

Une des dernières techniques est basée sur la croissance de Escherichia coli (24). Elle étudie la composition du milieu et les conditions d'incubation. En plus, elle envisage divers types d'extraction et retient le suivant: :hydrolyse en milieu aqueux tamponné à pH 4,5 avec de l'acétate de sodium et en protégeant la vitamine par addition de $\mathrm{I} \mathrm{mg}$ de cyanure de potassium par $\gamma$ de vitamine présente dans l'extrait.

I1 faut noter que Ochromonas dose spécifiquement la vitamine $\mathrm{BI} 2$ et non les cobalamines comme Escherichia coli (50).

Enfin, pour déceler les diverses vitamines $\mathrm{BI} 2$ et les dissocier d'autres facteurs de croissance on peut faire appel à un procédé mixte utilisant à la fois la chromatographie et la microbiologie : on mesure microbiologiquement 1'activité des vitamines $\mathrm{BI} 2$ après les avoir isolées chromatographiquement $(65 a, \mathrm{I} 79 a, \mathrm{I} 8 \mathrm{I} a)$. 


\section{E. - RÉSUltats COMPARATIFs ET CONCLUSIONS}

Après avoir passé en revue les trois grands types de dosages vitaminiques, les techniques biologiques, chimiques et microbiologiques, la question qui se pose est de savoir dans quelle mesure des résultats obtenus par des voies si différentes peuvent présenter entre eux une bonne concordance. Certains auteurs se sont posés la question et ont analysé un même échantillon à l'aide de techniques diverses. Nous allons donner le fruit de leurs travaux dans les tableaux suivants.

Dans chacun d'eux nous avons calculé les valeurs relatives moyennes en prenant arbitrairement une des techniques comme référence; ceci permet de mettre en lumière la similitude ou la divergence existant entre les méthodes de dosages. Encore conviendra-t-il de remarquer que la nature de l'échantillon peut intervenir dans le résultat d'une analyse vitaminique. C'est pourquoi, s'il existe pour chaque vitamine un mode usuel d'extraction, celui-ci ne peut être considéré comme valable dans tous les cas. Il y a notamment deux humeurs biologiques dont le dosage vitaminique offre des difficultés particulières: le sang et l'urine. Ces deux liquides exigent souvent une hydrolyse ou une purification particulières.

Les tableaux I et II mettent en lumière une très bonne concordance entre les trois modes de dosages de la vitamine BI.

Il faut noter que dans le tableau I les auteurs ont pris la précaution de calculer la valeur du "blanc" dans la technique de fermentation de la Levure.

Par ailleurs, dans ces deux tableaux concernant la thiamine, on observe une bonne harmonie entre les techniques quel que soit le type d'échantillon observé (céréales, levure, productions animales, etc.). En conclusion, le dosage de la thiamine semble parfaitement au point, et les diverses techniques fournissent des résultats dont les écarts sont de l'ordre dero p. Ioo.

Le tableau III illustre bien la difficulté rencontrée dans le dosage urinaire de la riboflavine. En purifiant l'urine de plus en plus - colonne $\mathrm{A}$ à colonne $\mathrm{C}-$ les résultats baissent au fur et à mesure, pour finalement coïncider avec ceux obtenus à l'aide de la technique microbiologique.

Les résultats du tableau IV fournissant les teneurs en riboflavine de divers types d'échantillons montrent une concordance satisfaisante entre les méthodes biologiques, microbiologiques et chimiques. Comme pour la vitamine $\mathrm{BI}$, les écarts moyens sont de l'ordre de ro $\mathrm{p}$. Ioo.

Le tableau $\mathrm{V}$ fait apparaître une très forte différence entre les teneurs en niagcine obtenues par voie microbiologique ou chimique ou par voie biologique : les analyses faites à l'aide d'animaux supérieurs fournissant 


\section{TABLEAU I}

\section{Thiamine.}

Comparaison de résultats obtenus par diverses méthodes (97).

A : Méthode microbiologique (Saccharomyces cerevisiae). Déduction du a blanc » obtenu après traitement au sulfite.

B : Méthode chimique (thiochrome).

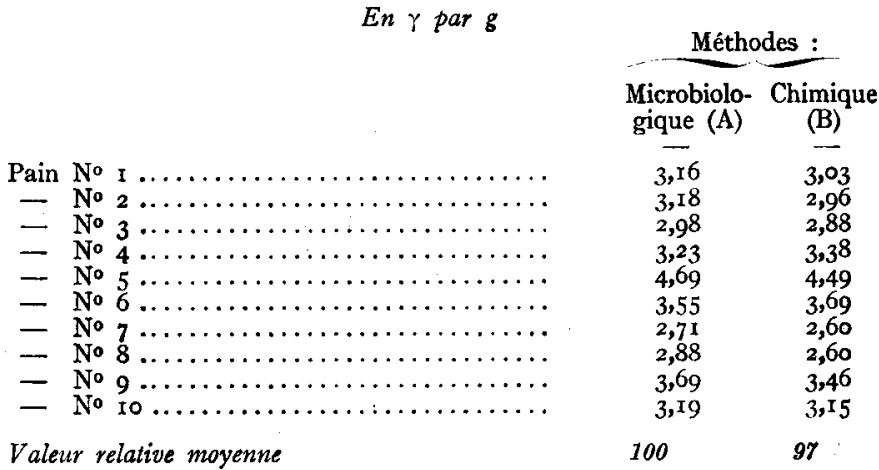

\section{TABLEAU II}

\section{Thiamine.}

Comparaisons. de résultats obtenus par diverses méthodes $(2 \mathrm{r}, 64)$.
A : Méthođes chimiques (thiochrome), Brown et coll. (2r).
B : Méthodes chimiques (thiochrome), Harris et coll. (63).
C : Méthodes biologiques (croissance du Rat).
$\mathrm{D}$ : Méthodes biologiques (bradycardie).

En $Y$ par $g$

Farine enrichie..

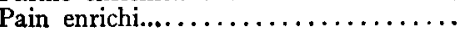

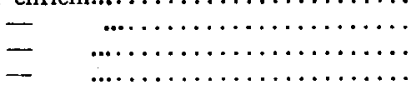

Pain blanc $\ldots \ldots \ldots \ldots \ldots \ldots \ldots \ldots \ldots \ldots \ldots$

Pain levure $\ldots \ldots \ldots \ldots \ldots \ldots \ldots \ldots$

Germe de blé $\ldots \ldots \ldots \ldots \ldots \ldots \ldots \ldots \ldots \ldots$
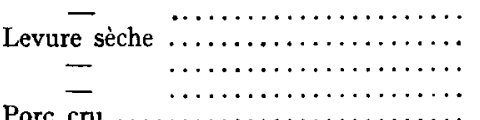

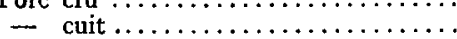

Lait écrémé en poudre .............

Euf : jaune ..................

$\rightarrow$ : blanc $\ldots \ldots \ldots \ldots \ldots \ldots \ldots$

Tablettes vitaminées.................

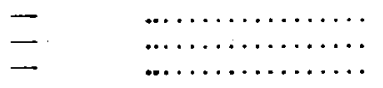

Valeur relative moyenne

Annales de Zootechnie. - I956.
Méthodes

\begin{tabular}{|c|c|c|c|}
\hline & & & \\
\hline & & & \\
\hline A & B & C & D \\
\hline- & — & $\cdots$ & - \\
\hline 6,3 & 一 & 7,0 & 一 \\
\hline 2,55 & - & 3,2 & - \\
\hline 4,0 & - & 4,4 & - \\
\hline 4,3 & - & 4,55 & 一 \\
\hline 3,85 & 一 & 4,45 & - \\
\hline $5, \mathrm{I}$ & - & 5,5 & - \\
\hline - & I,3 & $\cdots$ & $\mathbf{I}, 45$ \\
\hline - & 2,2 & - & 2,3 \\
\hline- & 4,25 & - & 4,35 \\
\hline - & 1,7 & 一 & 1,85 \\
\hline 28,3 & - & 32,0 & - \\
\hline- & 28,5 & 一 & 27,0 \\
\hline I 5,2 & - & I 7,9 & - \\
\hline - & I 4,5 & - & 17,0 \\
\hline- & 21,0 & - & 26,6 \\
\hline 一 & 23,0 & - & 27,0 \\
\hline - & I 5,5 & - & $14, I$ \\
\hline - & 2,55 & - & 2,65 \\
\hline- & 7,05 & 一 & 8,2 \\
\hline- & 0,15 & - & 0,03 \\
\hline 135,0 & - & I 50,0 & - \\
\hline 133,2 & - & I 50,0 & - \\
\hline I I 9,5 & - & I 50,0 & - \\
\hline $13^{6,9}$ & - & I 50,0 & - \\
\hline 88 & & 100 & \\
\hline & 93 & & 100 \\
\hline & & & \\
\hline
\end{tabular}




\section{TABLEAU III}

\section{Riboflavine.}

\section{Comparaison de résultats obtenus pour l'urine par diverses méthodes (129a).}

A : Méthode chimique, Rubin et Sevringhaus (I37).
B : Méthode chimique, Conner et Straub (29).
C: Méthode chimique, STater et Moreld (I55, I I 4 ).
D : Méthode microbiologique, SNELL et Strong (I 58 ).

\begin{tabular}{|c|c|c|c|c|c|}
\hline & & & & & \\
\hline & & & imiqu & & Microbiologique \\
\hline Sujet & Echantillon & A & B & C & D \\
\hline- & - & - & - & - & - \\
\hline$a \ldots \ldots \ldots$ & I & 880 & 790 & 一 & $73^{\circ}$ \\
\hline$-\ldots \ldots \ldots$ & 2 & 600 & 450 & 一 & 420 \\
\hline$-\ldots \ldots \ldots$ & 3 & 270 & IIO & - & 120 \\
\hline$-\ldots \ldots \ldots$ & 4 & 300 & 240 & - & 200 \\
\hline$-\ldots \ldots \ldots$ & 5 & 380 & 300 & - & $27^{\circ}$ \\
\hline$b \ldots \ldots \ldots \ldots$ & I & 890 & 700 & - & 570 \\
\hline$-\ldots \ldots \ldots \ldots$ & 2 & 280 & 130 & 一 & I 00 \\
\hline$-\ldots \ldots \ldots$ & 3 & 3 IO & 130 & 一 & 100 \\
\hline$-\ldots \ldots \ldots$ & 4 & $45^{\circ}$ & 190 & - & 190 \\
\hline$-\ldots \ldots \ldots \ldots$ & 5 & 260 & 130 & - & IIO \\
\hline$c \ldots \ldots \ldots \ldots$ & I & 59 & 62 & 33 & 33 \\
\hline$-\ldots \ldots \ldots \ldots$ & 2 & 75 & 80 & 45 & 43 \\
\hline$d \ldots \ldots \ldots$ & I & 60 & 72 & 44 & 39 \\
\hline$-\ldots \ldots \ldots \ldots$ & 2 & $6 \mathrm{I}$ & 84 & 53 & 50 \\
\hline ive moyenne: & & 187 & 133 & 106 & 100 \\
\hline
\end{tabular}

\section{TABLEAU IV}

\section{Riboflavine.}

Comparaison de résultats obtenus par diverses méthodes (45).

A : Méthode biologique (croissance du Rat).

B : Méthode microbiologique, SNELI et STRONG (I 59 ).

C : Méthode chimique, Kemmerer (86), lecture au fluorimètre.

D : Méthode chimique, Kemmerer (86),l ecture visuelle.

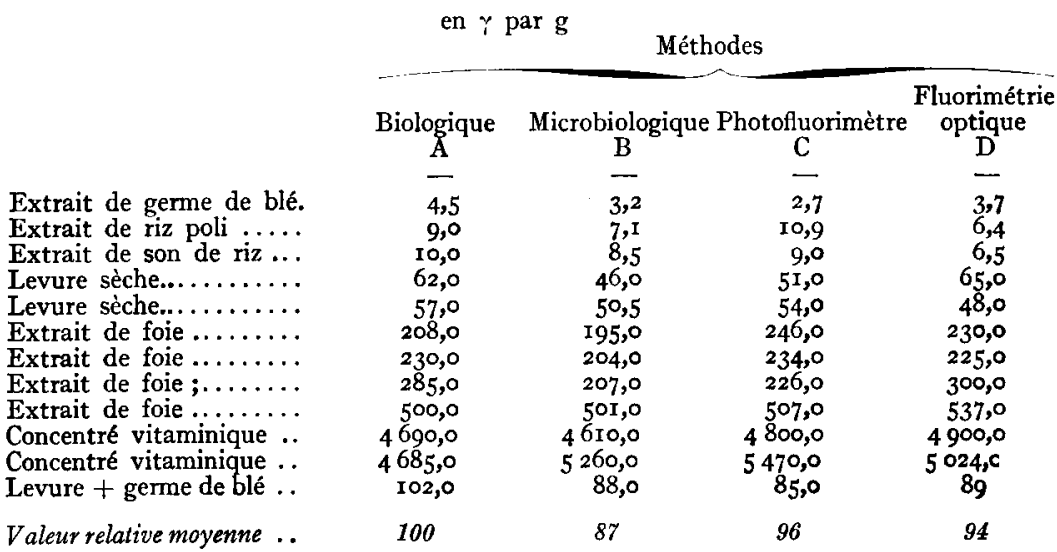




\section{TABLEAU V}

\section{Acide nicotinique.}

Comparaison de résultats obtenus par diverses méthodes. extraits d'une compilation dressée par Mc VICAR et BERRYMAN (I74).

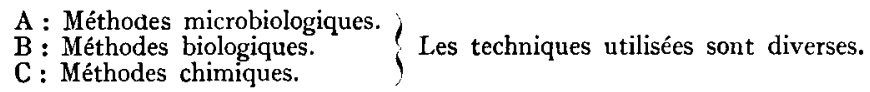

\begin{tabular}{|c|c|c|c|}
\hline & $\gamma$ par $g$ & Téthodes & \\
\hline & $\begin{array}{c}\text { Microbiologiques } \\
\text { A }\end{array}$ & $\begin{array}{c}\text { Biologiques } \\
\text { B }\end{array}$ & $\begin{array}{c}\text { Chimiques } \\
\mathrm{C}\end{array}$ \\
\hline Bouf & & & \\
\hline Cerveau .............. & 37,5 & 75,0 & 42,0 \\
\hline Cœur...$\ldots \ldots \ldots \ldots$ & 98,0 & 49,0 & 82,0 \\
\hline $\operatorname{Rein} . \ldots \ldots \ldots \ldots \ldots$ & 80,0 & 162,0 & 59,0 \\
\hline Poumon,$\ldots \ldots \ldots \ldots$ & 27,5 & 83,0 & 64,0 \\
\hline Foie .............. & I 17,5 & 265,0 & 146,0 \\
\hline Muscle...$\ldots \ldots \ldots$ & 45,0 & $3^{8,0}$ & 46,0 \\
\hline Mouton: & & & \\
\hline$\underset{\text { Porc: }}{\text { Foie }} \ldots \ldots \ldots \ldots \ldots \ldots$ & 105,0 & 425,0 & I 50,0 \\
\hline Fore $\ldots \ldots \ldots \ldots \ldots \ldots$ & 135,0 & 270,0 & I 93,0 \\
\hline Cœur ............... & 61,0 & 80,0 & 65,0 \\
\hline Rein..$\ldots \ldots \ldots \ldots$ & II 4,0 & I 55,0 & 83,0 \\
\hline Carré $\ldots \ldots \ldots \ldots \ldots$ & 38,0 & 88,0 & 64,0 \\
\hline Jambon............. & 40,0 & 83,0 & 58,0 \\
\hline Jambon fumé ......... & 36,0 & 82,0 & 70,0 \\
\hline Veau: & & & \\
\hline $\begin{array}{l}\text { Foie } \ldots \ldots \ldots \ldots \ldots \ldots \\
\text { Euf: }\end{array}$ & 125,0 & 225,0 & I 76,0 \\
\hline Jaune...$\ldots \ldots \ldots$ & $(0,35)$ & 40,0 & 10,0 \\
\hline B̈lanc $\ldots \ldots \ldots \ldots \ldots$ & $(0,75)$ & 25,0 & 7,0 \\
\hline Lait écrémé en poudre..... & 9,0 & 52,0 & I9,0 \\
\hline Farine d'arachide $\ldots \ldots \ldots \ldots$ & 172,0 & I 30,0 & I 94,0 \\
\hline Levure sèche $\ldots \ldots \ldots \ldots \ldots$ & 450,0 & 500,0 & 235,0 \\
\hline Levure sèche $\ldots \ldots \ldots \ldots \ldots$ & 500,0 & 635,0 & 355,0 \\
\hline Valeur relative moyenne .... & 100 & 199 & 121 \\
\hline
\end{tabular}

des résultats en moyenne deux fois plus élevés que ceux obtenus par les autres techniques. Ces écarts confirment parfaitement l'influence du tryptophane de l'échantillon comme facteur d'épargne de la niacine.

Ce tableau $\mathrm{V}$ ainsi que le suivant font ressortir une harmonie relativement bonne entre les méthodes chimiques et les techniques microbiologiques: 1'écart moyen le plus élevé est de $20 \mathrm{p}$. Ioo. Dans le tableau $\mathrm{V}$ les résultats chimiques sont plus élevés, et dans le tableau VI ce sont les valeurs provenant de la microbiologie qui sont les plus fortes: les deux méthodes fournissent des résultats qui se chevauchent.

Le tableau VII fait ressortir une certaine faiblesse des résultats microbiologiques concernant l'acide pantothénique vis-à-vis des résultats des dosages biologiques. Ceci est surtout vrai pour certains extraits de levure (colonne $\mathrm{B}$ et $\mathrm{D}$ ).

Par la suite, on a constaté qu'une extraction aqueuse ou à l'aide 


\section{TABLEAU VI}

\section{Acide nicotinique.}

Comparaison de résultats obtenus par diverses méthodes (64, I72).

A : Méthode chimique, Mc INTIRE et coll. (76).

B et $B^{\prime}$ : Méthode chimique, KoEnIG (9I).

C : Méthode microbiologique, SNELl et WRIGHT (160).

$\mathrm{D}$ : Méthode microbiologique, KoDICEK et PEPPER (90).

$\mathrm{E}:$ Méthode biologique (chien).

\begin{tabular}{|c|c|c|c|c|c|c|}
\hline & & $\gamma \mathrm{p}$ & & ethode & & \\
\hline & & himiq & & Micro & ogique & ologique \\
\hline & A & $\mathrm{B}$ & $\mathrm{B}^{\prime}$ & $\mathrm{C}$ & $\mathbf{D}$ & $\mathrm{E}$ \\
\hline & - & - & & $\ldots$ & $\ldots$ & - \\
\hline Pore: & & & & & & \\
\hline Carré ........... & 53,5 & 一 & & 59,0 & - & - \\
\hline Rein ........... & $\mathrm{I} 20,0$ & 一 & & I 4,0 & - & - \\
\hline Jambon $\ldots \ldots \ldots$ & 67,5 & - & & 70,0 & - & - \\
\hline${ }_{\text {Foie }} \ldots \ldots \ldots \ldots$ & I33,0 & - & & 95,0 & - & - \\
\hline Pancréas.......... & 45,0 & 一 & & 39,0 & - & - \\
\hline Muscle ............ & - & 36,5 & & - & $3^{6,5}$ & - \\
\hline Veau: & & & & & & \\
\hline Foie $\ldots \ldots \ldots \ldots$ & 127,0 & 一 & & 102,0 & 一 & 一 \\
\hline Culotte........... & 78,5 & 一 & & 72,5 & - & 一 \\
\hline Son $\ldots \ldots \ldots \ldots$ & - & 218,0 & & - & 250,0 & - \\
\hline Germe ......... & - & 66,5 & & - & 63,5 & - \\
\hline Farine $\ldots \ldots \ldots \ldots$ & - & 24,5 & & 一 & 23,0 & - \\
\hline Semoule ......... & - & rg,o & & - & 77,0 & - \\
\hline Mais : & & & & & & \\
\hline Farine $\ldots \ldots \ldots \ldots$ & - & I 5,5 & & - & I 5,0 & - \\
\hline Carotte............ & - & 4,5 & & - & 6,5 & - \\
\hline Euf séché........... & 一 & 4,0 & & - & 3,0 & - \\
\hline Lait frais $\ldots \ldots \ldots \ldots \ldots$ & 一 & $\mathrm{I}, \mathrm{O}$ & & - & $\mathbf{I}, \mathbf{O}$ & - \\
\hline Pomme de terre séchée & - & 90,0 & & - & 102,0 & - \\
\hline Muscle de rat......... & 一 & & 144,0 & 一 & - & I 35,0 \\
\hline Café $\ldots \ldots \ldots \ldots \ldots$ & - & & $45, \mathrm{o}$ & - & 一 & 47,5 \\
\hline Lait . ............ & 一 & & 0,6 & 一 & 一 & I,I \\
\hline 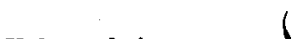 & & & 87 & & & \\
\hline Valeur relative moyenne & & 8 & & & 100 & \\
\hline
\end{tabular}

d'enzymes comme la mylase $P$ n'hydrolysait qu'une fraction seulement de la vitamine, et c'est pourquoi on pratiqua des extractions avec des phosphatases intestinales et des enzymes hépatiques (II5) ou des poudres de reins traités à l'acétone ( 47 a). Mais, selon les auteurs le bénéfice de ce nouveau type d'extraction était plus ou moins grand : certains voyaient les teneurs du foie augmenter de cinq fois (II5) tandis que d'autres obtenaient des résultats voisins (48).

De même l'autolyse du foie a fourni des résultats élevés (IOO, I05) ou non (I77) par rapport à l'extraction à l'aide de la mylase $P$.

En réalité, il semble qu'un travail récent départage assez bien les divergences concernant l'extraction et le dosage de l'acide pantothénique : 
le tableau VIII accorde à l'extraction à l'aide de phosphatase et d'enzymes hépatiques une supériorité de l'ordre de $30 \mathrm{p}$. Ioo par rapport à l'hydrolyse effectuée par la mylase $P$.

Le tableau IX confirme cet écart et montre une excellente coincidence entre la méthode biologique et la méthode microbiologique (extraction avec le mélange enzymatique).

Enfin, le tableau $X$ fait apparaître une très bonne concordance entre les techniques chimique et bactériologique, mais ces chiffres portent exclusivement sur des échantillons de céréales, et il serait intéressant d'étendre la comparaison à d'autres catégories de substances biologiques ou alimentaires.

En conclusion, il paraît sage de ramener à de justes proportions là divergence signalée entre les divers modes d'extraction de l'acide pantothénique.

Nous n'avons pas trouvé de tableaux comparatifs présentant des analyses en vitamines $\mathrm{B} 6$ et en biotine.

Le tableau XI permet de penser que le dosage de l'acide folique est pratiquement au point car on ne relève pas de grandes divergences entre les résultats des méthodes chimique, microbiologique et biologique.

Il ne parait pas que les choses en soient là en ce qui concerne le dosage de la vitamine BI2. LILLIE et coll. (IO2 a), viennent de consacrer une étude à la comparaison des méthodes biologiques et microbiologiques de dosage de la vitamine $\mathrm{BI} 2$.

Leurs résultats sont groupés dans les tableaux XII et XIII, ceux-ci sont nettement différents l'un de l'autre: le premier donne des exemples d'échantillons qui offrent les mêmes valeurs lorsqu'ils sont traités par la technique biologique ou par la méthode microbiologique, tandis que dans le tableau XIII apparaît une complète anarchie entre les deux techniques analytiques. I1 semble donc exister des cas d'espèces, mais, ce qui surprend est que l'on trouve dans les deux tableaux des produits très voisins et même identiques (farine de poisson). Par ailleurs toutes les méthodes microbiologiques ne fournissent pas des résultats comparables, ce qui fait conclure qu'à l'heure actuelle les techniques analytiques concernant la vitamine $\mathrm{Br} 2$ ne sont pas encore satisfaisantes.

Par contre, étant donné l'ancienneté de la vitamine $\mathrm{C}$ et les très nombreux travaux qu'elle a suscités, son dosage est parfaitement mis au point. Le tableau XIV en donne une preuve si besoin est.

En résumé, pour les facteurs vitaminiques dont les modalités analytiques sont actuellement bien étudiées, les différents modes de dosage fournissent des résultats identiques à Io $\mathrm{p}$. Ioo près environ.

Que doit-on penser d'une telle marge ?

Tout d'abord qu'il est et sera impossible de la réduire : il existera toujours une imprécision de cet ordre entre des laboratoires différents et 
TABLEAU VII

\section{Acide pantothénique.}

Comparaison de résultats obtenus par diverses méthodes ( $\mathrm{II} 4 b, \mathrm{I} 64)$.

A : Méthode microbiologique (hydrolyse aqueuse), STrong et coll. (I64).

$B$ : Méthode microbiologique (hydrolyse avec clarase), NEAL et coll. (1 I $_{4} b$ ).

$\mathrm{C}$ et $\mathrm{D}$ : Méthodes biologiques (poulet).

\begin{tabular}{|c|c|c|c|c|}
\hline & oar & Mé & & \\
\hline & Micr & ques & & \\
\hline & $\mathbf{A}$ & $\mathrm{B}$ & $\mathrm{C}$ & D \\
\hline Levure: & - & - & - & - \\
\hline Poudre................ & 1.37 & 一 & I65 & - \\
\hline Poudre................ & 170 & - & 200 & - \\
\hline Fxtrait ............... & - & I34 & - & 200 \\
\hline Extrait .............. & $-\ldots$ & 187 & - & 220 \\
\hline Extrait $\ldots \ldots \ldots \ldots \ldots$ & - & 123 & - & 190 \\
\hline Extrait $\ldots \ldots \ldots \ldots \ldots \ldots$ & - & 298 & - & 510 \\
\hline Extrait $\ldots \ldots \ldots \ldots \ldots \ldots$ & - & 132 & - & 250 \\
\hline Foie: & & & & \\
\hline Extrait ................ & 370 & 一 & 300 & 一 \\
\hline Extrait $\ldots \ldots \ldots \ldots \ldots \ldots$ & 213 & - & 300 & - \\
\hline Extrait $\ldots \ldots \ldots \ldots \ldots \ldots$ & $5^{65}$ & - & 600 & - \\
\hline Extrait $\ldots \ldots \ldots \ldots \ldots$ & 448 & - & $45^{\circ}$ & - \\
\hline Extrait ................ & 338 & - & 360 & 一 \\
\hline Extrait $\ldots \ldots \ldots \ldots \ldots \ldots$ & I 98 & - & 300 & - \\
\hline Extrait .............. & 548 & - & 600 & - \\
\hline Euf : & & & & \\
\hline $\begin{array}{l}\text { Jaune...................... } \\
\text { Bouf : }\end{array}$ & $7^{2}$ & - & $5^{6}$ & - \\
\hline Muscle $\ldots \ldots \ldots \ldots \ldots$ & IO & - & Io & - \\
\hline Rein $\ldots \ldots \ldots \ldots \ldots$ & 44 & - & 27 & - \\
\hline Orge $\ldots \ldots \ldots \ldots \ldots \ldots \ldots \ldots$ & 43 & - & $5^{6}$ & - \\
\hline Contenu de rumen...$\ldots \ldots \ldots$ & 90 & - & 92 & - \\
\hline Lait écrémé séché............ & 46 & - & 46 & $\rightarrow$ \\
\hline Son de blé. $\ldots \ldots \ldots \ldots \ldots \ldots$ & 48 & - & 46 & - \\
\hline Son de blé................ & $4 \mathrm{I}$ & $\cdots$ & $3^{8}$ & - \\
\hline Valeur relative moyenne...... & 90 & & 100 & \\
\hline & & 66 & & 100 \\
\hline
\end{tabular}

Comparaison de résultats obtenus par voie microbiologique à l'aide de divers types d'extraction ( $\mathrm{I} 73 a$ ).

Méthode microbiologique, SkEggs et coll. (154).

\begin{tabular}{|c|c|c|c|}
\hline & Ext & raction & \\
\hline & $\begin{array}{l}\text { Phosphatase intes- } \\
\text { tinale plus enzymes } \\
\text { du foie }\end{array}$ & $\underset{\mathbf{P}}{\text { Mylase }}$ & $\begin{array}{c}\text { Sans } \\
\text { enzymes }\end{array}$ \\
\hline & - & - & - \\
\hline Bouf (viande maigre) ........ & 24,3 & 17,6 & 8,7 \\
\hline Carotte.$\ldots \ldots \ldots \ldots \ldots$ & 20,7 & 14,8 & 14,2 \\
\hline Poudre d'œuf entier ........... & 76,2 & 65,9 & 50,7 \\
\hline 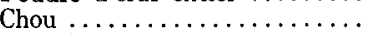 & 69,4 & 47,5 & $4 I, 4$ \\
\hline Arachide $\ldots \ldots \ldots \ldots \ldots \ldots \ldots$ & 23,8 & I 5,4 & I 2,4 \\
\hline Foie de porc. $\ldots \ldots \ldots \ldots \ldots$ & 203,0 & 142,0 & 96,0 \\
\hline 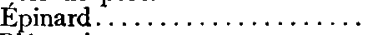 & 21,6 & I 5,5 & 9,3 \\
\hline Blé entier ................ & 11,0 & 7,6 & 5,9 \\
\hline Levure $\ldots \ldots \ldots \ldots \ldots \ldots \ldots$ & I 17,6 & 58,8 & 46,3 \\
\hline 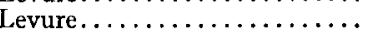 & 89,3 & 56,8 & 8,0 \\
\hline Valeur relative moyenne........ & 100 & 69 & 48 \\
\hline
\end{tabular}


appliquant chacun des méthodes plus ou moins modifiées dans leur détail. Par conséquent, en considérant une imprécision de cet ordre de grandeur, que peut-on attendre des résultats analytiques concernant les vitamines hydrosolubles ?

\section{TABLEAU IX}

\section{Acide pantothénique.}

Comparaison de résultats obtenus par diverses méthodes ( $\mathrm{I}_{73}$ a).

A : Méthode microbiologique, SKEgGs et coll. (154).

B : Méthode biologique, Croissance du Rat.

\begin{tabular}{|c|c|c|c|}
\hline & $\underset{\mathrm{B}}{\text { Biologique }}$ & $\underset{\mathrm{A}}{\text { Microbiolo }}$ & gique \\
\hline & & $\begin{array}{c}\text { extraction avec } \\
\text { phosphatase et } \\
\text { enzymes } \\
\text { hépatiques }\end{array}$ & $\begin{array}{l}\text { extraction } \\
\text { avec } \\
\text { Mylase } \mathrm{P} .\end{array}$ \\
\hline Carotte. & $\overline{35.7}$ & $\overline{20,7}$ & $\overrightarrow{148}$ \\
\hline Poudre ouf entier........... & 65,19 & 76,2 & 65,9 \\
\hline Chou,$\ldots \ldots \ldots \ldots \ldots \ldots$ & 56,2 & 69,5 & 47,6 \\
\hline Arachide $\ldots \ldots \ldots \ldots \ldots \ldots$ & 25,4 & 25,5 & 17,2 \\
\hline Foie de porc............. & 176,7 & 203,0 & $\mathrm{I} 42,0$ \\
\hline Levure de brasserie..$\ldots \ldots \ldots$ & I 38,0 & 117,6 & 58,8 \\
\hline Valeur relative moyenne...... & 100 & 99 & 69 \\
\hline
\end{tabular}

\section{Acide pantothénique.}

Comparaison de résultats obtenus par diverses méthodes (126 a).

A : Méthode chimique, Szalkowski et coll. (I69).

B : Méthode microbiologique, SkEGGs et coll. (1 54 ).

en $\gamma$ par $g$

Race de blé :

$T$. Monococcum $\ldots \ldots \ldots \ldots \ldots \ldots \ldots \ldots \ldots \ldots \ldots \ldots \ldots \ldots \ldots$
$T$. diococcum $\ldots \ldots \ldots \ldots \ldots \ldots \ldots$

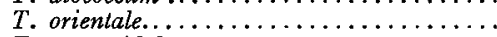

T. pyramidale $\ldots \ldots \ldots \ldots \ldots \ldots \ldots \ldots$

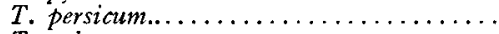

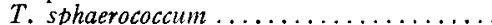

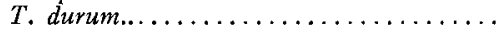

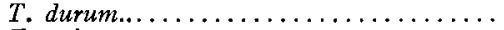

T. vulgave

Hard Red Spring $\ldots \ldots \ldots \ldots \ldots \ldots$

Hard Red Spring ...............

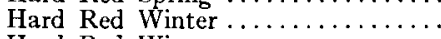

Hard Red Winter
Méthodes

Chimique Microbiologique

A

B

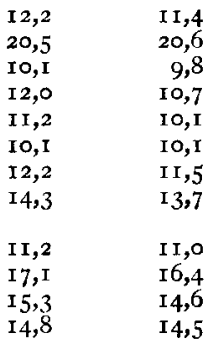

100

95 


\section{TABLEAU XI}

\section{Acide folique.}

Comparaison de résultats obtenus par diverses méthodes (I, I4 a).

A : Méthode chimique, Allfrey et coll. (I).

$\mathrm{B}$ et B' : Méthode microbiologique. RoBERTS et SNELI (13I).

C : Méthode biologique. Poulet.

en $\gamma$ par $g$
Méthodes

\begin{tabular}{cccc} 
Chimique & \multicolumn{2}{c}{ Microbiologique } & Biologique \\
A & B & B' & C \\
- & - & - & - \\
0,29 & 0,23 & - & - \\
0,27 & 0,20 & - & - \\
0,29 & 0,20 & - & - \\
0,13 & 0,10 & - & 55,0 \\
- & - & 50,0 & 50,0 \\
- & - & 52,0 & 50,0 \\
- & - & 57,0 & 25,0 \\
- & - & 26,0 & 200,0 \\
- & - & 199,0 & 8135,0 \\
- & - & 7670,0 & 54,0 \\
- & - & 26,0 & 54,0 \\
- & - & 59,0 & 98,0 \\
- & - & 89,0 & 12,0 \\
133 & 100 & 7,0 & \\
& & & 119
\end{tabular}

\section{TABLEAU XII}

Vitamine B12.

Comparaison de résultats obtenus par diverses méthodes ( 102 a).

A : Méthode biologique, Croissance du Poulet, Bird et coll. (1 $5 a$ ),

B : Méthode microbiologique (extraction en présence de CNNa). Pharmacopée U. S. (I 2 I a).

en $\gamma$ par $g$

Farine de crabe

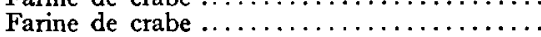

Farine de hareng......................

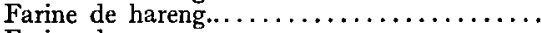

Farine de saumon..$\ldots \ldots \ldots \ldots \ldots \ldots \ldots \ldots$

Farine de thon.

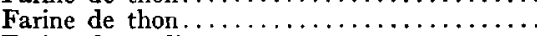

Farine de sardine $\ldots \ldots \ldots \ldots \ldots \ldots \ldots \ldots$

Solubles de poisson ....................

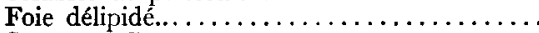

Concentré Biz $\ldots \ldots \ldots \ldots \ldots \ldots \ldots \ldots \ldots$

Valeur relative moyenne
Méthodes

Biologique Microbiologique

\begin{tabular}{ccc} 
A & B \\
\hline 0,33 & & 0,45 \\
0,56 & & 0,62 \\
0,23 & & 0,27 \\
0,18 & & 0,19 \\
0,09 & & 0,14 \\
0,10 & & 0,19 \\
0,18 & & 0,13 \\
0,23 & 0,17 \\
0,06 & 0,04 \\
0,69 & 0,90 \\
2,26 & & 3,30 \\
00 & & 120
\end{tabular}




\section{TABLEAU XIII}

\section{Vitamine B12.}

Comparaison de résultats obtenus par diverses méthodes (I02 a).

A : Méthode biologique, Croissance du Poulet, BIRD et coll. (I $5 a$ ).

B : Méthode microbiologique (extraction en présence de CN Na). Pharmacopée U. S. (121 a).

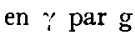

Poudre de foie $\ldots \ldots \ldots \ldots \ldots \ldots \ldots \ldots \ldots \ldots$

Solubles de poisson ...................

Solubles de poisson $\ldots \ldots \ldots \ldots \ldots \ldots \ldots \ldots$

Solubles de poisson $\ldots \ldots \ldots \ldots \ldots \ldots \ldots \ldots \ldots \ldots$

Solubles de poisson $\ldots \ldots \ldots \ldots \ldots \ldots \ldots \ldots$

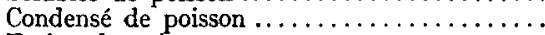

Farine de poisson $\ldots \ldots \ldots \ldots \ldots \ldots \ldots \ldots$

Farine de viande $\ldots \ldots \ldots \ldots \ldots \ldots \ldots \ldots$

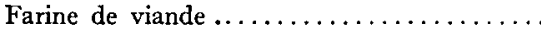

Concentré de jus d'herbe...............
Méthodes

\begin{tabular}{cc}
\hline Biologique & Microbiologique \\
\cline { 2 - 2 } & $\mathrm{B}$ \\
5,75 & - \\
0,98 & 0,58 \\
0,75 & 0,12 \\
0,39 & 0,28 \\
0,57 & 0,14 \\
$0,8 \mathrm{I}$ & 0,28 \\
0,24 & 0,10 \\
0,08 & 0,06 \\
$0, \mathrm{I} 6$ & 0,04 \\
0,08 & 0,06 \\
& $0,0 \mathrm{r}$
\end{tabular}

\section{TABLEAU XIV}

\section{Acide ascorbique.}

Comparaison de résultats obtenus par diverses méthodes (64).

A : Méthode chimique (dichlorophénolindophénol).

B : Méthode biologique (croissance ou tests dentaires) $(62,12)$.

en mg par $g$

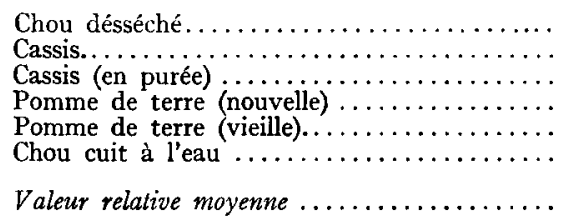

\begin{tabular}{|c|c|}
\hline \multicolumn{2}{|c|}{ Méthodes } \\
\hline \multicolumn{2}{|c|}{ Chimique (A) Biologique (B) } \\
\hline$\overline{4,60}$ & $\overline{4}_{4}$, \\
\hline 2,37 & 1,94 \\
\hline 1,20 & 1,28 \\
\hline 0,35 & 0,37 \\
\hline 0,09 & 0,07 \\
\hline 0,25 & 0,25 \\
\hline 108 & 100 \\
\hline
\end{tabular}

Il convient de distinguer ici deux sortes de travaux :

- Dans un travail de physiologie, le but principal est la mise en évidence d'une différence entre un lot témoin et des lots expérimentaux. Dans ce cas, en choisissant une méthode analytique les risques d'entraîner une erreur relative tout au long du travail ne sont pas très importants, en ce sens que cette erreur se retrouvant partout, elle ne faussera pas les conclusions que l'on tirera du travail.

- Il n'en va plus de même dans un travail nutritionnel, où l'on doit arriver à une valeur absolue. Il faut, par exemple, déterminer dans quelle mesure une ration couvre les besoins vitaminiques d'un organisme donné. 
Dans ce cas, il faut savoir avec quelles difficultés sont déterminés les besoins vitaminiques de 1'Homme ou des animaux. Il est permis alors de penser que l'imprécision de ces standards est égale ou supérieure à celle des dosages vitaminiques.

C'est pourquoi, nous conclurons que lorsque les modalités analytiques sont bien étudiées, la précision des dosages est suffisante en regard de la notion des besoins vitaminiques.

\section{RÉFÉRENCES BIBLIOGRAPHIQUES}

\section{Traités Généraux.}

(a) The Association of vitamin chemists. Methods of vitamin assay. I vol., New-York, Interscience Publishers Inc. édit.

(b) Gyorgy (P.). - Vitamin methods, 2 vol., New-York I950, Academic Press. Inc. édit.

(c) Johnson (B. C.). - Methods of vitamin determination, I vol., Minneapolis I948, Burgess Publishing Co, Minneapolis édit.

(d) LEDERER (E)., LEDERER (M.). - Chromatography, I vol., Amsterdam I954, Elsevier Publishing Co édit.

(e) Robinson (F. A.). - The vitamin B complex, I vol., Londres I947, Chapman et Hall édit.

(f) Sebreli, (W. H.jr), Harris (R. S.). - The vitamins, 3 vol., New-York I954, Academic Press Inc. édit.

(g) WeLsch (M.). - Le dosage microbiologique des vitamines, I vol., Liège I947, Desoer édit.

\section{$2^{\circ}$ Articles et mémoires originaux cités.}

(I) Allfrey (V.), Teply (L. J.), Geffen (C.), King (C. G.). - J. Biol. Chem., I939, 178, 465-8I.

(2) Ansbacher (S.), LAndy (M.). - Proc. Soc. exp. biol. med., I94I, 48, 3.

(3) Atkin (L.), Schultz (A. S.), Wilimams (W. L.), Frey (C. N.). - Ind. eng. chem. Anal. ed., I943, 15, I4I.

(4) Bacon (J. S. D.), Jenkins (G. N.), Irwin (J. O.). - Biochem. J., I943, 37, 492 .

(5) Bacon (J. D. S.), Jenkins (G. N.). - Biochem. J., I943, 37, 392.

(6) BARGer (G.), Berger, (F.), TOdD (A. R.). - Nature, I935, 136, 259.

(7) BASU (K. P.), NaTh (M. C.). - J. indian chem. soc., I938, 15, I33.

(8) Bauernfeind (J. C.), Sotier (A. L.), BorufF (C. S.). - Ind. eng. chem. Anal. ed., I942, 14, 666-7I.

(9) Bender (R. C.), SuppleE (G. C.). - J. Nutrit., I940, 20, IO9.

(IO) Bessey (O. A.), Lowry (O. H.), Love (R. H.). - J. Biol. chem., I949, 180, 755-69.

(II) Bina (A. F.), Thomas (J. M.), Brown (E. B.). - J. biol. chem., I943, 148, III.

(I2) Birch (T. W.), Harris (I. J.), Ray (S. N.). - Biochem. J., I933, 27, 590.

(I3) Birch (T. W.), Harris (L. J.). - Biochem. J., I934, 28, 602.

(I4) BIRCH ('T. W.). - J. biol. chem., I938, 124, 775 .

(I4 a) Bird (O. D.), Bressler (B.), Brown (R. A.), Campbeli (C. J.), Emmett (A. D.). - J. biol. chem., I945, 159,63I.

(15) Bird (O. D.), Robbins (M.), VAndenbeíi (J. M.), Pfiffner (J. J.). J. biol. chem., I946, 163, 649-59. 
(I5 a) Bird (H. R.), Rubin (M.), Groschke (A. C.). - J. biol. chem., I948, 174, 6II-9.

(I6) Bird (O. D.), Vandenbelt (J. M.), EmmetT' (A. D.). - J. biol. chem., I942, 142, 3I7.

(I7) BLISS (C. I.), Gyorgy (P.). - Vitamin methods II. New-York I95I, Acad. Press., édit.

(I8) Bourquin (A.), Sherman (H. C.). - J. am. chem. soc., I93I, 53, 350 I.

(I9) BoXer (G. E.), Rickards (J. C.). - Arch. bioch., I952, 39, 28 I-6.

(20) Bratton (A. C.), Marshal, (E. K. jr). - J. biol. chem., I939, 128, 537.

(2I) Brown (E. B.), Hamm (J. C.), Harrison (H. E.). - J. biol. chem., I943, 151, I53-6r.

(22) Burch (H. B.), Bessey (O. A.), Lowry (O. H.). - J. Biol. chem., I948, $175,457,70$.

(23) Burch (H. B.), Bessey (O. A.), Love (R. H.), Lowry (O. H.). - J. biol. chem., I952, 198, 477-90.

(23 a) Buskirk (H. H.), Bergdahl (A. M.), Delor (R. A.). - J. biol. chem., I948, 172, 67I-5.

(24) CALET (C.), RERAT (A.). - Ann. Zootech., I954, 3, 247-70.

(25) ClaARKe (M. F.), LEChyCKA (M.). - J. Nutrit., I943, 25, 57 I.

(26) Coates (M. E.), Kon (S. K.), ShepHeard (E. E.). - Brit. J. nutrit., I950, 4, 203.

(27) Coates (M. E.), Ford (J. E. ), Harrison (G. F.), Kon (S. K.), Shepheard (E. E.), WILBY (F. W.). - Brit. J. Nutrit., I952, 6, 75.

(28) Conger (T. W.), Elvehjem (C. A.). - J. biol. chem., I94I, 138, 555.

(29) Conneir (R. T.), Strraub (G. J.). - Ind. eng. chem. Anal. ed., I94I, 13, 385-8.

(30) Coward (K. H.), Burn (J. H.), Ling (H. W.), Morgan (B. G. E.). Biochem. J., I933, 27, I7I9.

(3I) COWARD (K. H.). - Biochem. J., I936, 30, 20 I2.

(32) Coward (K. H.), Morgan (B. G. E.). - Biochem. J., I939, 38, 658.

(33) Coward (K. H.). - The biological standardization of vitamins, I vol. I947, Baltimore, W. Woodand Co édit.

(34) CROKaERT (R.). - Bull. soc. chim. biol., I949, 31, 903-7.

(35) Daft (F. S.), Schwarz (K.). - Fed. proc., I952, 11, 20 I.

(36) DANIEL (E. P.), K LINE (O. I..). - J. biol. chem., I947, 1\%0, 739-46.

(37) Day (P. L.), Darby (W. J.). - Biol. symposia, I947, 12.

(38) Eddar (C. E.), Ei SAdR (M. M.), MacraE (T. F.). - Biochem. J., I938, $32,2200$.

(39) Edie (E. S.), Evans (W. H.), Moore (B.), Simpson (G. C. E.), WEBSTER (A.). - Biochem. J., I9I2, 6, 234.

(40) Van Eikelen (M.). - Acta. brev. Neerland. Phys. Pharm. Microbiol., I934, 4, I37.

(4I) Eiringer (P.), Abder, Kader (M. M.). - Biochem. J., r949, 44, 77 et 627.

(42) Ei Sadr (M. M.), Macrae (T. F.), Work (C. E.). - Biochem. J., I940, 34, 6or.

(43) EMmerie (A.). - Biochem. J., I934, 28, 268.

(44) EMMmerie (A.). - Rec. Trav. chim., I939, 58, 290.

(45) Emmet't (A. D.), Bird (O. D.), Brown (R. A.), Peacock (G.), VandenBELT (J. M.). - Ind. eng. chem. Anal. ed., I94I, 13, 2 I9-2I.

(46) Von Euler (H.), Martius (C.). - Ann., I933, 505, 73.

(47) Von Euler (H.), Malmberg (M.). - Z. Physiol. Chem., I937, 250, 158.

(48) Evans (R. J.), Groschke (A. C.), Butts (H. A.). - Arch. biochem., I95I, 31, 454-6.

(49) Ferrebee (J. W.). - J. clin. Invest., I940, 19, 25 I.

(50) Ford (J. E.). - Brit. J. Nutr., I953, r, 299-306.

(5I) Fox (S. W.), MCNEIL, (E. W.), FIELD (H. jr). - J. Biol. chem., I943, $14 \%, 645$. 
(52) Friedemann (T. E.), Frazien (E. I.). - Arch. biochem., I950, 26, 36I-74.

(53) Frost (D. V.), Fricke (H. H.), Spruth (H. C.). - Proc. soc. exp. biol. med., I949, 72, I02.

(54) Fujita (A.), Matsuu Ra (K.). - J. Biochem. Japon, I950, 37, 445.

(55) Gannon (C. F.), McGovern ('T.). - Proc. soc. exp. biol. med., 1938, 38, 267.

(55 a) Gaudiano (A.). - Rend. Ist. Super. Sanita Rome, I954, 17, 59I-60o.

(56) GibBs (H. D.). - J. biol. chem., I927, 72, 649.

(57) Glazko (A. J.), Wolf (L. M.). - Arch. biochem., I949, 21, $24 \mathrm{I}-2$.

(58) Gould (B. S.), Schwachman (H.). - J. biol. chem., I943, 151, 439.

(59) Guerrant (N. B.), Vavich (M. G.), Fardig (O. B.). - Ind. eng. chem. Anal. ed., 1945, 17, 7Io.

(6o) Gyorgy (P.). - J. Nutrit., I938, 16, 69.

(6I) GyoRgy (P.). - Vitamin methods II, New-York, I95I, Acad. Press édit.

(62) Harris (L. J.), RAy (S. N.). - Biochem. J., I933, 27, 303.

(63) Harris (L. J.), WANG (Y. L..). - Biochem. J., I94I, 35, I050.

(64) Harris (L. J.)., Mapson (L. W.), Kodicek (E.), Moore (T.), Booth (V. H.). - Ann. Nutr. Alim., I949, 3, 25-48.

(65) HaRRIS (I. J.), KOdICEK (E.). - Brit. J. Nutrit., I950, 4, XIII.

(65 a) Harrison (J. S.). - Analyst, I95I, 76, 77.

(66) Hegsted (D. M.), Oleson (J. J.), Mirls (R. C.), Eldehjem (C. A.), HART (E. B.). - J. Nutrit., I940, 20, 599.

(67) Hegsted (D. M.), Lipmann (F.). - J. biol. chem., I948, 174, 89-92.

(67 a) Heimann (W.), Strohecker (R.), Matt (F.). - Z. Lebensmittel. Unters. Forsch., I953, 97, 263-70.

(68) Hennessy (D. J.), CERECEdo (L. R.). - J. am. chem. Soc., I939, 61, I79.

(69) Hoag (E. H.), SARETT (H. P.), CheidDELIN (V. H.). - Ind. eng. chem. Anal. ed., $1945,17,60-2$.

(70) Hochberg (M.), Meinick (D.), Oser (B. L.). - J. biol. chem., I944, 155, 109 .

(7I) Hodson (A. Z.), Norris (L. C.). - J. biol. chem., I944, 131, 62 I.

(72) Hoffer (A.), Alcock (A. W.), Geddes (W. F.). - Cereal chem., I939, 21, 5I5.

(73) HOJER (J. A.). - Brit. J. exp. pathol., I926, 7, 356.

(74) Huff (J. W.), PerizWeig (W. A.), Til,Den (M. W.). - Fed. proc., I945, 4, 92 et $J$. biol. chem., I947, 167, I57-67.

(75) Hutchings (B. L.)., Stokstad (E. L. R.), Boothe (J. H.), Mowat (J. H.), Waller (C. W.), ANgier (R. B.), Semb (J.), Subbarow (Y.). - J. biol. chem., I947, 168, 705-IO.

(76) Mcintire (J. M.), Waisman (H. A.), Heinderson (L. M.), Ellvehjem (C. A.). - J. Nutrit., I94I, 22, 535 .

(77) ISBELl (H.), Wooley (J. G.), Fraser (H. F.). - U. S. Pub. health Rep., I $94 \mathrm{I}, \mathbf{5 6}, 282$.

(78) Jacouot (R.), ARMand (Y.), REY (P.). - Bull. soc. sci. hyg. alim., I94I, 29, I-7I.

(79) Jansen (B. C. P.). - Z. Vitaminforsch, I938, 7, 226 et 239.

(80) Jansen (B. C. P.), Westendrink (H. G. K.).-Rec.trav. chim., Pays-Bas, I940, 59, 76r.

(8i) Jansen (B. C. P.), Donath (W. F.).- Proc. K. Akad. Wetensch. Amsterdam, I926, 29, I390.

(82) JANSEN (A. P.). - Rec. trav. chim., I950, 69, 1275.

(83) Jukes (T. H.). - J. Nutrit., I937, 14, 223.

(84) Jukes ('T. H.), Heitman (H.). - J. Nutrit., I940, 19, 2 I.

(85) Jukes (T. H.). - J. Nutrit., I943, 21, I93.

(86) KEMMERER (A. R.). - J. assoc. Off. agr. chem., I940, 23, 346.

(87) KEY (K. M.), ElphICK (G. K.). - Biochem. J., I93I, 25, 888. 
(88) Kinnersiet (H. W.), Peters (R. A.). - Biochem. J., I928, 22, 4I9 et I933, 27, 225 et 232.

(89) KLATZIEN (C.), NoRris (F. W.), WokEs (F.). - J. pharm. and pharmacol. I949, 1, 9I5.

(90) KODICEK (E.), PEPPER (C. R.). - J. gen. Microbio, I948, 2, 292-3I4.

(9I) KOENIG (W.). - J. pratk. chem., I904, 69, I05 et 70, I9.

(92) Kornberg (H. A.), Langdon (R. S.), Cheldeilin (V. H.). - Ind. eng. chem. Anal. ed., I948, 20, 8I-3.

(93) Koschara (W.). - Z. physiol. chem., I935, 232, Ior.

(94) KREHI, (W. A.), Strong (F. M.), ElivehJEM (C. A.). - Ind. eng. chem. Anal. ed., I943, 15, 47I.

(95) Krehl (W. A.), Sarma (P. S.), Teply (L. J.), Elyvehjem (C. A.). - J. Nutrit., I946, 31, 85.

(96) KUHN (R.), LOEW (I.). - Ber., I939, 72, I453.

(97) Laemte, Barlow. - Ceréal chem., 1942, 19, 540.

(98) Laskowski (M.), Mrms (V.), DaY (P. L.). - J. biol. chem., I945, 15\%, $73 I-9$.

(98 a) Leifer (E.), Roth (L. J.), Hogness (E. S.), Corson (M. H.). - J. biol. chem. I95I, 190, 595 .

(99) LEVITON (A.). - J. am. chem. soc., I946, 68, 835-40.

(IOo) LEVy (G.), Giroud (A.). - Bull. soc. chim. biol., I953, 35, 507-Io.

(IOI) LEWIS (U. J.), Register (U. D.), ElveHJEM (C. A.). - Proc. soc. exp. biol. med., I949, 71, 5og.

(IO2) Lim (H.), King (T. E.), Higgins (H.), Baumann (C. A.), Strong (F. M.). - J. Nutrit., I95I, 44, 36I-70.

(IO2 a) LILLIE (R. J.), SIZEMORE (J. R.), KELIOG (W. J.), DeNTON (C. A.). Poultry Sci., I954, 33, 686-9I.

(I03) Lunde (G.), KRINGSTAd (H.), Olsen (A.). - Z. physiol. chem., I939, 260, I4I.

(IO4) Mannering (G. J.), Orsini (D.), Ellvehjem (C. A.). - J. Nutrit., I944, 28, I4I.

(I05) MARNAy (C.). - Bull. soc. chim. biol., r953, 35, 220-4.

(I05 a) MARTEN (G.). - Intern. Z. Witamin. forsch., I955, 25, 392-40r.

(Io6) Mar'tini, Bonsignore. - Biochem. Z., I934, 273, I70.

(IO7) MELAIICK (D.), Field (H.). - J. biol. chem., I939, 127, 505, 5I5, 53 I.

(Io8) Meinick (D.), Hochberg (M.), Himes (H. W.), Oser (B. L.). - J. biol. chem., I945, 160, I.

(IO9) Mentzer (C.), Vialard-Goudou (A.). - Bull. soc. chim. biol., I937, 19, 707-I9.

(Iro) Meunier (P.). - Ann. Ferm., I937, 3, I57.

(III) Mindin (R. L.), ButLer (A. M.). - J. biol. chem., I938, 123, 673-86.

(II2) Mr'rchel, (H. K.), SNeil, (E. E.). - Publication Univ. Texas, I946, $\mathbf{n}^{0} 4 \mathrm{I} 37,36$.

(II3) Moreli, (D. B.). - Austral. J.exp. biol. med. Sc., I947, 25, 25I.

(II4) MORELL (D. B.), Silater (E. C.). - Biochem. J., I946, 40, 652-7.

(II4 a) NAJJAR (V. A.), Ketron (K. C.). - J. biol. chem., I944, 152, 579.

(II4 b) NeAL (A. I.), Strong (F. M.). - Ind. eng. chem. Anal. ed., I943, $15,654-7$.

(II5) Neilands (J. B.), Strong (F. M.). - Arch. biochem., I948, 19, $287-9$ I.

(i16) Ormsby (A. A.), Fisher (A.), Schlenk (F.). - Arch. biochem., I947, 12,79 . 